\title{
Heat and Freshwater Transport through the Central Labrador Sea*
}

\author{
F. STRANEO \\ Department of Physical Oceanography, Woods Hole Oceanographic Institution, Woods Hole, Massachusetts
}

(Manuscript received 27 February 2004, in final form 17 August 2005)

\begin{abstract}
The seasonal and interannual variations in the export of Labrador Sea Water (LSW), and in the heat and freshwater transport through the central Labrador Sea, are examined for two different periods: from 1964 to 1974, using Ocean Weather Station Bravo data, and from 1996 to 2000, using data collected from profiling floats. A typical seasonal cycle involves a 300-m thickening of LSW (convection) followed by an equivalent thinning (restratification). Restratification is characterized by a drift of properties toward boundary current values that is indicative of a vigorous lateral exchange. The net result is a convergence of heat and salt, between 200 and $700 \mathrm{~m}$, that balances the net surface heat loss to the atmosphere and partially offsets the surface freshwater accumulation due to surface, lateral exchange. Interannual variations in the export of LSW can be explained by taking into account changes in the central Labrador Sea-boundary current density gradient, which governs the lateral exchange. Interannual variations in how much heat is converged into the region, on the other hand, mostly reflect changes in the temperature of LSW. This only partly explains, however, the increased convergence of heat that occurs during the late 1990s. In years in which convection does not occur, restratification trends continue throughout the entire year, albeit at a reduced rate.
\end{abstract}

\section{Introduction}

Like most of the subpolar North Atlantic Ocean, the Labrador Sea experiences a net annual heat loss to the atmosphere. As a deep/intermediate convection region, however, it is unique in distributing this heat loss over a depth of a kilometer or more, thus releasing heat from density classes that are typically not exposed to the atmosphere. The heat loss is balanced in turn by a convergence of heat into the region due to the oceanic circulation and, as such, the Labrador Sea is an important contributor to the net poleward heat transport by the ocean-atmosphere system. Similarly, freshwater of Arctic origin, advected around the basin by the surface boundary currents, contributes to a large, surface accumulation of freshwater in the late spring and summer. This freshwater is mixed downward during convection, resulting in a considerable freshening of the intermediate layers. As such, the Labrador Sea plays a role in the

*Woods Hole Oceanographic Institution Contribution Number 11052.

Corresponding author address: Dr. Fiammetta Straneo, Woods Hole Oceanographic Institution, MS 21, Woods Hole, MA 02543. E-mail: fstraneo@whoi.edu vertical redistribution of freshwater, thus contributing to the removal of freshwater anomalies (Houghton and Visbeck 2002) and to the recently observed freshening of the intermediate waters of the North Atlantic (Dickson et al. 2002).

To first order, the Labrador Sea is a semienclosed basin characterized by narrow, swift cyclonic boundary currents and a large interior, mostly quiescent region (Lavender et al. 2000), where deep convection occurs (Clarke and Gascard 1983; Pickart et al. 2002). The principal source of heat for the basin is warm, modified North Atlantic Current water, or "Irminger Water," that circulates around the subpolar gyre and is advected into the basin, between 200 and $700 \mathrm{~m}$, by the cyclonic boundary system (Cuny et al. 2002; Lazier et al. 2002). From the boundary current, heat is then supplied to the interior region through eddies predominantly due to boundary current instabilities (Lilly et al. 2003; Katsman et al. 2004; Spall 2004). Above the Irminger Water layer, cold and fresh surface waters are advected around the basin by the West Greenland and Labrador Currents and, again, it is the lateral exchange with these boundary currents that gives rise to the seasonal freshening (and cooling) of the surface waters of the interior (Lazier 1980).

Somehow, this combination of surface heat loss, lat- 
eral convergence of heat, and freshwater contribute to sustaining deep to intermediate convection in the Labrador Sea. This is true even despite the considerable interannual variability of convection, from the shutdown for several years in the early 1970s to the extreme convection to $2300 \mathrm{~m}$ in the early 1990s (Lazier 1980; Lazier et al. 2002). Yet, our knowledge and understanding of what regulates the heat and freshwater exchange between the convection region and the boundary current are very limited. We do not know, for example, how the removal of heat by the atmosphere and the supply of heat by the ocean are related. Clearly, the answer will vary depending on the time scale in which one is interested. Seasonally, the bulk of the heat loss occurs over the winter while observations from the central Labrador Sea show both a rapid, late spring import of heat, but also a slower prolonged import of heat throughout the remainder of the year (Lilly et al. 1999). Interannually, attempts to correlate the change in heat content in the interior with the net heat loss (or even with the extent of convection) have proved mostly unsuccessful (Smith and Dobson 1984; Lilly et al. 2003; Lazier et al. 2002). In a steady-state sense (i.e., averaging over many years), one would expect the two to balance.

In general, our knowledge of the magnitude, vertical structure, and seasonal and interannual variability of the lateral exchange is limited, as is our understanding of the factors that control it. Earlier modeling studies treated the convection region as isolated, and the lateral fluxes that restratified it were driven by the convective process itself (Jones and Marshall 1997; Visbeck et al. 1996). More important, the boundary currents that ultimately provide the source of buoyant water for the convection region, as well as the means of removing the dense water, were not present in these studies. Recently, modeling studies have started to include boundary currents and have shown that the continuous exchange between the convection region and these currents plays a fundamental role in setting the extent of convection and the properties of the dense water formed (Spall 2004; Katsman et al. 2004). For the most part, though, these studies have been fairly idealized and limited to a system where density is a function of temperature alone.

In this study, historical (from 1964 to 1974) and modern (from 1996 to 2000) data are used to estimate the net contribution, vertical partitioning, and seasonal and interannual variability of the lateral exchange of properties in the central Labrador Sea. The first dataset is that of the hydrographic measurements made at Ocean Weather Station Bravo (OWSB). While the net contribution of the lateral fluxes has been discussed before
(Lazier 1980; Smith and Dobson 1984; Ikeda 1987), the seasonal and vertical decomposition proposed in this study are new. A second dataset was constructed from roughly 800 Profiling Automatic Lagrangian Circulation Explorer (P-ALACE) float temperature and salinity profiles obtained from the central Labrador Sea, mostly in the vicinity of the original Bravo station. Both datasets are effectively representative of a subregion within the western portion of the central Labrador Sea (slightly larger for the float data). This implies that the analysis conducted in this study is for this region only. At the same time, there is some degree of spatial homogeneity in the Labrador Sea's interior [see, e.g., the October 1996 section in Pickart et al. (2002)], which suggests that these estimates may be representative of the larger Labrador Sea interior. Estimates from both datasets are compared in an effort to diagnose factors that may affect the lateral exchange. The comparison is interesting because while the two periods share some similarities (e.g., in being weak to intermediate convection periods) there are also some basic differences: the entire water column of the Labrador Sea has freshened since the 1960s (Dickson et al. 2002). Furthermore, the weather station data contain the only documented shutdown of convection on record, from 1969 to 1971. The basic features of the two datasets are reviewed in section 3.

A knowledge of the surface fluxes is crucial if one is to estimate the lateral fluxes at a depth that is at some point contained within the mixed layer. Since the mixed layer in a convection region extends to intermediate/ deep depths, the surface fluxes effectively impact a significant portion of the water column. As discussed in section 2, estimates of the surface heat fluxes appear to be converging (with some uncertainty), but there is still much to be done in terms of the surface freshwater fluxes.

Before extracting the lateral fluxes, the seasonal and interannual variations in the heat and salt content of the surface to intermediate water column, in the central Labrador Sea, are presented in section 4 . The seasonal, interannual, and mean annual contributions of the lateral fluxes, both over the entire water column and divided into a surface (which contains much of the seasonal variability) and lower layer, are discussed in section 5. Since it is proposed that the lateral exchange is, to a large degree, controlled by the interior-boundary current density gradient, the analysis is extended beyond heat and salt by considering the lateral exchange of the convectively formed Labrador Sea Water (LSW) (section 6). The findings of this study, and their implications, are summarized and discussed in section 7 . 


\section{The surface fluxes}

\section{a. The surface heat flux}

Estimates of the surface heat fluxes in the Labrador Sea region still involve considerable uncertainties. Extensive reviews and improvements of the bulk formulas using in situ observations are discussed both in Smith and Dobson (1984), for the early OWSB data, and in Moore and Renfrew (2002) following wintertime observations during the Labrador Sea Deep Convection Experiment (Lab Sea Group 1998). Smith and Dobson's (1984) corrected bulk formulas yield a mean annual heat loss of $28 \mathrm{~W} \mathrm{~m}^{-2}$, much less than previous estimates. The National Centers for Environmental Protection-National Center for Atmospheric Research (NCEP-NCAR) reanalysis fields, as quoted in Lazier et al. (2002), for the 1990s yield a much larger mean heat flux of $70 \mathrm{~W} \mathrm{~m}^{-2}$, which, even when taking into account the interannual variability, is in disagreement with Smith and Dobson's estimates. By comparing in situ observations and NCEP-NCAR data, Renfrew et al. (2002) found that the model overestimated both the sensible and latent heat fluxes because of the poor performance of the algorithms under extreme wintertime conditions. This led to a correction of the bulk algorithms that resulted in a noticeable decrease in the net surface heat fluxes (Moore and Renfrew 2002; Renfrew et al. 2002). The mean surface heat loss from the recalibrated NCEP-NCAR fields is of $28.5 \mathrm{~W} \mathrm{~m}^{-2}$ (or equivalently of $0.891 \times 10^{9} \mathrm{~J} \mathrm{~m}^{-2}$ ), which is close to Smith and Dobson's (1984) earlier estimate.

This study utilizes the recomputed monthly mean NCEP-NCAR reanalysis total surface heat flux (latent plus sensible plus longwave and shortwave contribution), which was implemented for the 1948-2000 period (K. Moore 2001, personal communication). The mean seasonal cycles (averaged over the central Labrador Sea) for the different periods, the OWSB, float, and the entire climatology (1948-2000), are shown in Fig. 1a. The amplitude of the seasonal signal (approximately $180 \mathrm{~W} \mathrm{~m}^{-2}$ ) is much greater than the interannual variability. The latter is characterized by a wintertime standard deviation of $60 \mathrm{~W} \mathrm{~m}^{-2}$, whereas the summertime is limited to $10 \mathrm{~W} \mathrm{~m}^{-2}$ (these were obtained by removing the mean seasonal cycle from the 1948-2000 total heat flux time series). The heat gain from May to September is approximately only $30 \%-40 \%$ of the heat loss during the remainder of the year (Fig. 1b). The standard deviation of the net annual heat loss $(0.43$ $\times 10^{9} \mathrm{~J} \mathrm{~m}^{-2}$, where the net loss for $1 \mathrm{yr}$ is obtained by integrating the heat flux from May of the preced- ing year to April of the year in question) is quite large, amounting to approximately one-half of the net annual loss; see Fig. 1c.

\section{b. Evaporation-precipitation}

Direct measurements of evaporation $(E)$ and precipitation $(P)$ in the region are scarce, thus making the accuracy of $E-P$ estimates for this region questionable because of uncertainties in both fields. Estimates of the mean annual precipitation vary from $0.8 \mathrm{~m} \mathrm{yr}^{-1}$ (Ikeda 1987) to $1 \mathrm{~m} \mathrm{yr}^{-1}$ (Lazier 1980) to a recent estimate of $1.26 \mathrm{~m} \mathrm{yr}^{-1}$ by Sathiyamoorthy and Moore (2002, SM02 hereinafter). The former values are inferred from precipitation measurements over land in neighboring regions. The latter estimate is based on in situ observations of weather conditions (at OWSB from 1949 to 1972) using Tucker's (1961) algorithm to infer precipitation. Evaporation is estimated from the latent heat flux data and is thus susceptible to errors in the latent heat flux algorithm. Using the recomputed NCEPNCAR data, SM02 derive a mean annual evaporation of $0.75 \mathrm{~m}$ for the period from 1949 to 1972 . Because of the uncertainties in both fields, $E-P$ net annual estimates range from $-0.05 \mathrm{~m} \mathrm{yr}^{-1}$ [Lazier et al. (2002), from NCEP-NCAR reanalysis data prior to the recomputation of Renfrew et al. (2002)] to $-0.5 \mathrm{~m} \mathrm{yr}^{-1}$ [SM02; and da Silva climatology for the period 1945-93, da Silva et al. (1994)].

The large uncertainty in $E-P$ automatically implies a large uncertainty in the lateral freshwater fluxes, which are calculated as a residual having removed the annual $E-P$. The $0.5 \mathrm{~m}$ of freshwater required to annually balance the observed salinity changes at OWSB (Lazier 1980 ) could therefore either result from $E-P$ alone or from lateral advection alone. The latter hypothesis being that most quoted in the literature (Lazier 1980; Lazier et al. 2002; Khatiwala et al. 2002).

In this study, the seasonal climatological $E-P$ obtained by SM02 is used given it is the most recent estimate; see Fig. 2. A comparison of $E-P$ from SM02 with that from da Silva et al. (1994) shows similar seasonal variability with $P$ exceeding $E$ over the entire year, and maximum freshwater flux in the winter (Fig. 2a). The net freshwater gain is $-0.55 \pm 0.19 \mathrm{~m} \mathrm{yr}^{-1}$ for SM02 and $-0.59 \pm 0.18 \mathrm{~m} \mathrm{yr}^{-1}$ for da Silva et al. (1994) (Fig. $2 b)$. Because neither record covers the time period of both datasets, calculations in this study will utilize the climatological $E-P$ flux from SM02, and any interannual variability is necessarily neglected. From both records, the interannual variability in the net annual heat loss is limited in comparison with the net freshwater gain (not shown). 

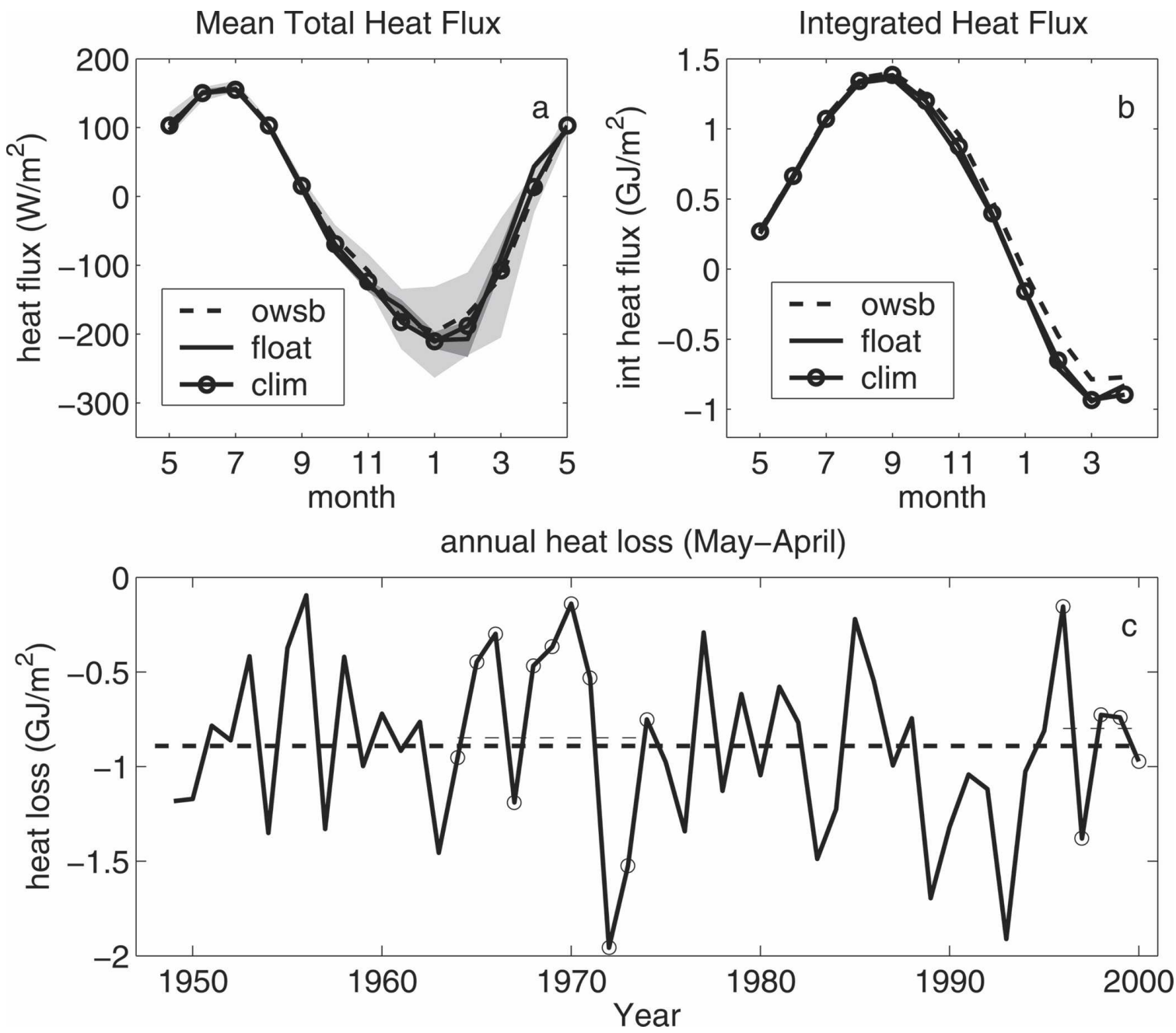

FIG. 1. (a) Mean surface heat flux from the recalibrated NCEP-NCAR reanalysis data for 1948-2000 (clim), for the OWSB period, and for the float period. Shaded areas show the standard deviation for the two data periods (dark for the floats). (b) Annually integrated heat loss from May to April, same periods as above. (c) Interannual variation of the annual heat loss (from May of the preceding year to April of the indicated year). Circles indicate OWSB and float years, and the horizontal lines indicate the mean heat loss over the three periods.

\section{The 1960s and late 1990s in the Labrador Sea}

\section{a. The two datasets}

Two datasets are considered in this study. From January 1964 to September 1974, oceanographic data were collected at the OWSB (see Fig. 14 for location) with variable sampling rates (from $6 \mathrm{~h}$ to 2 months). The data used in this study were originally interpolated to standard depth levels and linearly interpolated for months where the data were missing (11 months total in the full dataset). A comprehensive review of these data can be found in Lazier (1980) and Smith and Dobson (1984). The second dataset, from January 1996 to December 2000, is constructed from approximately 900 temperature and conductivity profiles collected by $\mathrm{P}$ -
ALACE floats [see Lavender et al. (2005) for a general description of the float dataset] in the central Labrador Sea (CLS-here defined as that area roughly bounded by the 3300-m isobath; see Fig. 14). A single monthly temperature and salinity profile, representative of the CLS water column, was obtained by horizontally averaging properties (see the appendix for a comprehensive description of the filtering, averaging, and calibration techniques utilized). While the two datasets have seemingly different spatial coverage (the OWSB data were collected at a single location while the float data were distributed over much of the CLS) in practice the majority of the float profiles were collected within $200 \mathrm{~km}$ of the Bravo location. Hence, to first order, both datasets are mostly representative of the western por- 

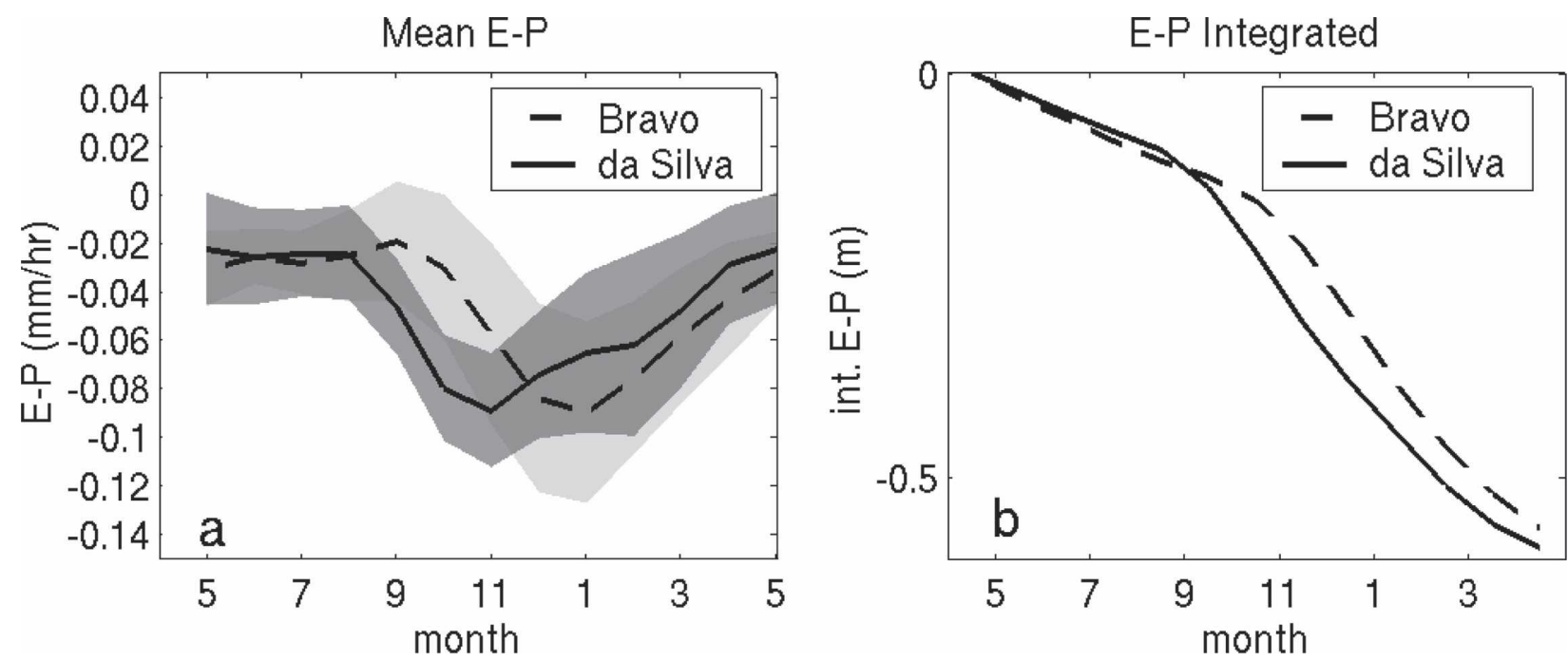

FIG. 2. (a) Monthly mean climatological $E-P$ flux from the Bravo record (1949-73) estimated by Sathiyamoorthy and Moore (2002) and from the da Silva climatology [1945-93, da Silva et al. (1994)]. The standard deviation is shaded. (b) Integrated E-P from May to April for the same records as in (a).

tion and hence of the region of deepest convection (Clarke and Gascard 1983; Pickart et al. 2002).

\section{b. General features of the data}

Before delving into a quantitative analysis of these two records, it is useful to consider the general features of the convective cycle, the surface forcing, and the history of convection for both periods. Properties for both periods are shown in Fig. 3. A strong seasonal cycle, which dominates the variability in the upper 200 $\mathrm{m}$, is superimposed upon interannual variations, which are, instead, more evident at depth. In the surface waters, one can easily discern the seasonal heating and cooling cycle of the surface forcing, combined with a seasonal freshening. Convection, occurring in the later winter or early spring, tends to mix the excess fresh and cold water into the lower layers.

While there is some interannual variability in the surface heat fluxes during both records (Fig. 1), it is also evident that the mid-1960s (prior to 1972) and the late 1990s are similar in that they are characterized by relatively weak forcing. This, in turn, contributed to relatively weak convection throughout the float record and prior to 1972 in the OWSB record (Lazier 1980; Lazier et al. 2002; Yashayaev 2004). As a result of reduced convective activity, and hence of the reduced mixing of cold and fresh waters into the lower water column, one sees the progressive warming and salinity increase of the lower layers (Fig. 3). This is particularly evident for the float record since it follows a period of intense convection in the early 1990s, when a persistently high phase of the North Atlantic Oscillation resulted in anomalously large surface buoyancy losses. What one sees at depth, then, is the progressive flushing of the anomalously cold and fresh LSW that was formed during the early 1990s (Lazier et al. 2002; Yashayaev 2004).

The most striking disruption of the seasonal cycle occurs in the OWSB record, toward the end of the 1960s. During this time a large freshwater anomaly, the Great Salinity Anomaly (GSA; Dickson et al. 1988), circulated around the basin and resulted in an anomalously fresh surface layer in the Labrador Sea's interior, from the end of 1968 to the beginning of 1972 . The increased stability due to this excess freshwater, combined with the reduced atmospheric heat loss during that period (Fig. 1), resulted in the shutdown of deep convection with mixed layer deepening limited to the upper $200 \mathrm{~m}$ (Lazier 1980). Convection resumed in 1972 as a result of the strongest winter on record (Fig. 1) and produced an anomalously cold and fresh vintage of LSW (Lazier 1995).

Last, it is noted that the float years are characterized by a colder and fresher water column than was present throughout the earlier part of the OWSB record (prior to 1972). The freshening of waters in the Labrador Sea from the 1960s to the 1990s is discussed by Dickson et al. (2002).

\section{Heat and salt content}

The goal of this study is to diagnose and quantify the transport of heat and freshwater through the CLS and 

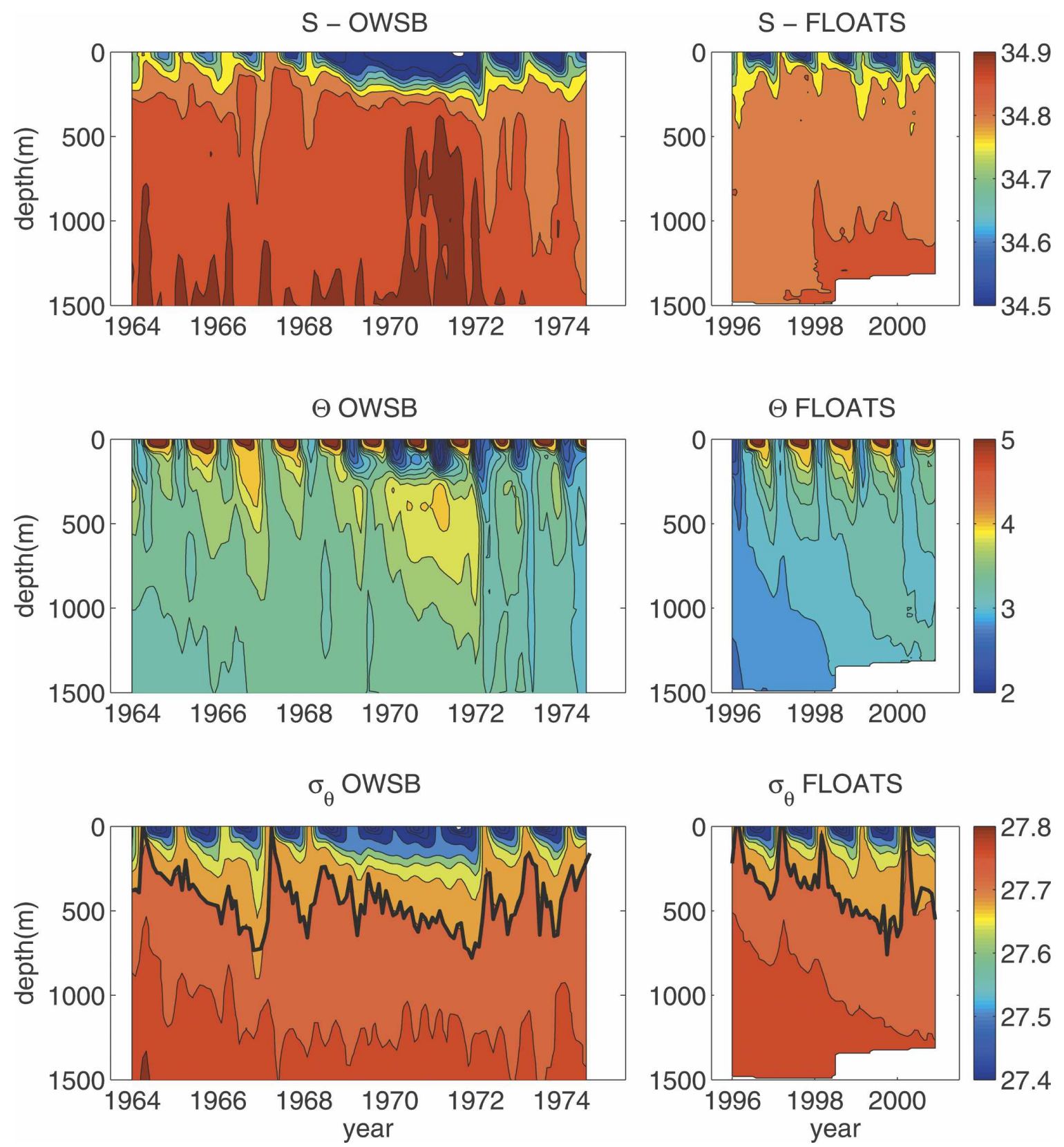

FIG. 3. (left) OWSB and (right) float datasets: (top) salinity (psu), (middle) potential temperature $\left({ }^{\circ} \mathrm{C}\right.$ ), and (bottom) potential density $\left(\mathrm{kg} \mathrm{m}^{-3}\right)$ with $\sigma_{\theta}=27.72$ overlaid as a thick black line.

identify the processes involved, paying particular attention to the vertical structure of the lateral fluxes (representing the CLS-boundary current exchange). Earlier studies that have addressed this question have mostly focused on annual budgets over a large portion of the water column (typically 0-1500 m). Such temporal and vertical averaging, however, is likely to shed little insight on a region characterized by a strong seasonal cycle and surrounded by boundary currents with an evident vertical structure (cold, freshwater overlying the warm, salty Irminger Water).

Critical to diagnosing the lateral fluxes is the ability to separate that portion of the water column affected by the surface fluxes (the mixed layer) from that beneath it. Given the relatively low temporal resolution of the OWSB data and the horizontal averaging used in deriving the float data, however, defining and following the mixed layer evolution is not feasible. Instead, a 
more basic partitioning of the water column is proposed in this study: a surface layer $(0-200 \mathrm{~m})$ and a lower layer (200-1300 m). (The 1300-m cutoff is set by the extent of much of the float data, and for the sake of comparison is also used in analyzing the OWSB data.) The rationale behind this choice is the following. Except during a limited time period in the late winter/early spring when convection occurs, the mixed layer is contained within the surface layer. Hence, it is reasonable to assume that, outside of this period, the lower layer is isolated from the surface fluxes. A related feature of the surface layer is that it contains the bulk of the seasonal cycle, as noted by Lazier (1980) and Lilly et al. (2003), hence separating the surface and lower layers allows one to extract the interannual variability. Last, but again likely related, the bulk of the warm, Irminger Water is mostly found beneath $200 \mathrm{~m}$ in the boundary current [see the section in Fig. 9 as well as in Pickart et al. (2002) or Cuny et al. (2002)]. The analysis presented below supports the notion that this partitioning is physically significant, as exemplified by the different properties' trends exhibited by the two layers. At the same time, by grouping the top $200 \mathrm{~m}$ in a single layer one is not resolving the true thickness of the fresh and cold layer, which "invades" the central Labrador Sea immediately following convection and is possibly including some of the warm Irminger Water contribution to this layer. Efforts to resolve the thin surface layer in the OWSB are discussed in Lazier (1980), Ikeda (1987), and Kuhlbrodt et al. (2001).

\section{a. Interannual variations}

The heat and salt content variations for both the entire water column, and for the surface and lower layers, are shown in Fig. 4. As pointed out by Lazier (1980) and Lilly et al. (2003), the seasonal variability $O(2-3$ $\mathrm{GJ}$ ) is greater than, or on the order of, the interannual variability and is mostly contained in the surface layer (Figs. 4c and 4d). Changes in the lower layer, on the other hand, reflect longer-term trends that can, in general, be attributed to the history of convection (Figs. 4a and $4 \mathrm{~b}$ ). For example, weak convection periods (at the beginning of the OWSB record, or throughout the float record) are associated with an increase in heat content (see also Lazier 1980; Lazier et al. 2002), while strong convection events (e.g., during 1972) can dramatically lower the heat content of the entire water column (see also Lazier 1980). Note also, by comparing Figs. 4a and $4 \mathrm{~b}$, how the water column in the OWSB record (prior to 1972) was on average 2 GJ larger than that during the float record. This is attributed to the anomalously cold LSW vintage produced during the prolonged, and ex- treme, convection events of the early 1990s (Lazier et al. 2002).

As for heat, the bulk of the seasonal cycle in salinity is contained in the surface layer, while the lower layer mostly reflects the interannual trends (Figs. 4e-h). Changes in the surface layer are, in general, accompanied by opposite changes in the lower layer. This decoupling is all the more evident during the GSA years when the surface layer freshened while the lower layer became saltier (Figs. 4e and 4g). Unlike for heat, one sees no long-term trend in salinity in the float years. It appears, instead, that the salt content increased from 1996 to 1998 , but decreased beyond 1998. It is worth pointing out that the salinity data from the floats were calibrated using hydrographic data (see the appendix), and therefore that the interannual variability in the salt content is due to the hydrographic measurements.

\section{b. Mean seasonal cycle}

For numerous oceanographic and climate applications such as annual budgets of heat and freshwater, or comparison with models, it is of interest in identifying a "mean seasonal cycle" of properties in the region. The seasonal variation of properties, with respect to the annual mean, is computed for the total water column ( 0 $1300 \mathrm{~m}$ ), the surface, and lower layers; see Fig. 5. Three important features can be inferred from this figure. First, that there does indeed exist a mean seasonal cycle for properties and that, to a large extent, it is similar within the two periods. Second, that property variations in the surface and lower layers are characterized by distinct trends, which supports the physical significance of the layer partitioning. Third, one can identify two distinct periods within the seasonal cycle of properties: a restratification period and a convection period. Restratification (roughly May-December) is associated with a warming and increase in salt content ${ }^{1}$ of the lower layer and a freshening of the surface layer. During convection (January-April), these trends are reversed. For the total and surface layers' heat content, the signal that dominates is the sinusoidal character of the surface forcing. Qualitatively, the different trends can be interpreted as follows. During restratification, the mixed layer is entirely contained within the surface layer and the surface fluxes are acting on this layer alone. At this time, any change in the lower layer must be dominated by the lateral exchange with the surrounding ocean, which is mostly warmer and saltier (mostly due to the Irminger Water circulating around

\footnotetext{
${ }^{1}$ The noisy signal in the lower OWSB data is attributed to the uncertainty in the salinity measurements at the time (Lazier 1980).
} 

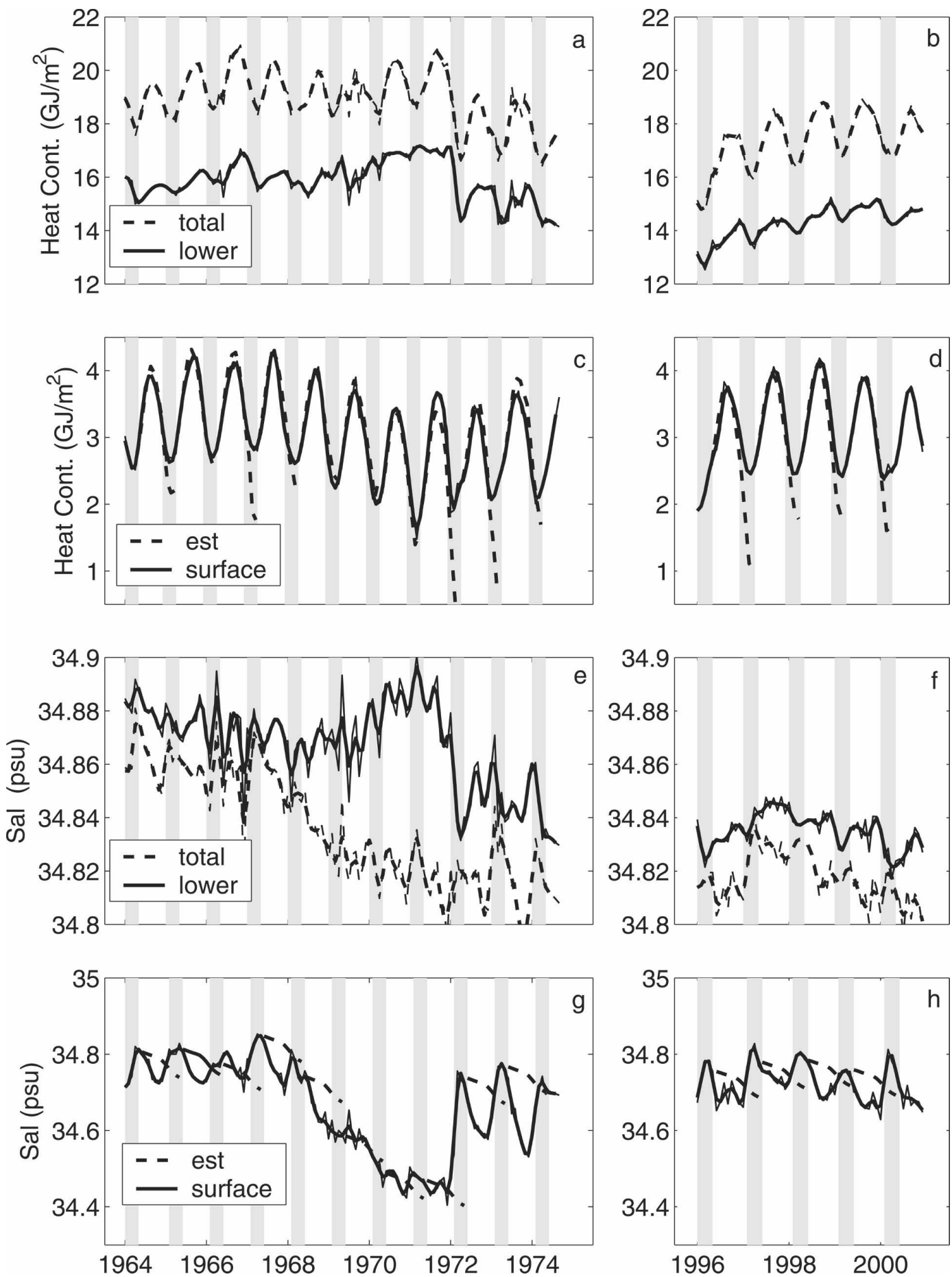

FIG. 4. (top two rows) Vertically integrated heat content and (bottom two rows) vertically averaged salinity for the two datasets: (left) OWSB and (right) floats. Thick lines are the 4-month low-pass-filtered results, thin is unfiltered. Shaded regions indicate the "convection period" from January to April. (a) Heat content in the 0-1300-m layer (dashed) and in the lower layer (200-1300 m, solid) for the OWSB data. (b) Same as in (a) but for float data. (c) Heat content for the surface layer (0-200 m, solid) for the OWSB data; overlaid is the estimated heat content change from the surface fluxes ("est," dashed). (d) Same as in (c) but for float data. (e) Salinity in the 0-1300-m layer (dashed) and in the lower layer (200-1300 m, solid) for the OWSB data. (f) Same as in (e) but for float data. (g) Salinity in the surface layer (0-200 m, solid) for the OWSB data; overlaid is the estimated salinity change from the $E-P$ surface flux ("est," dashed). (h) Same as in (g) but for float data. 
total
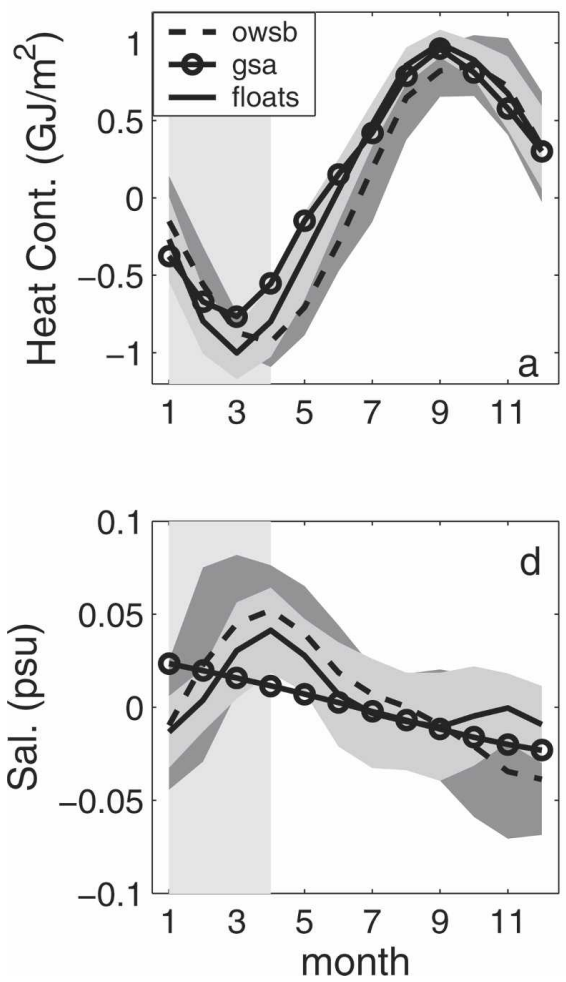

surface
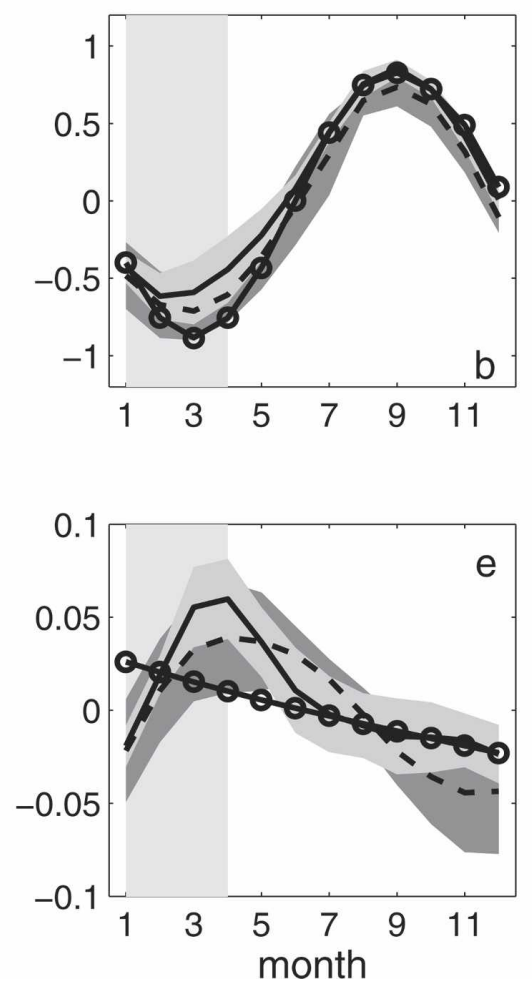

lower

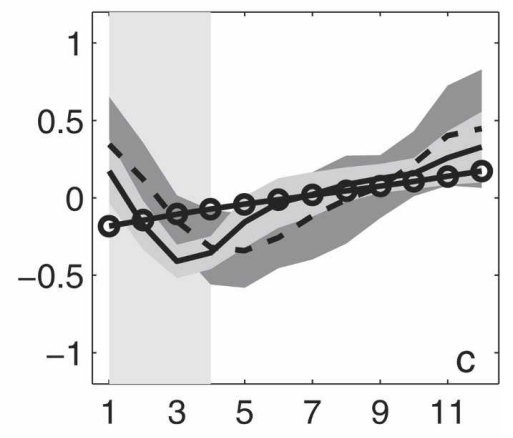

FIG. 5. Seasonal variation in heat content and salinity for the (left) total, (middle) surface, and (right) lower layers in the two datasets. Shading around each curve is the standard deviation. The convection period is vertically shaded. For the OWSB data, the curve labeled as "owsb" is the average over all non-GSA years, while the mean cycle averaged over the three GSA years is shown separately: (a) total layer, heat; (b) surface layer, heat; (c) subsurface layer, heat; (d) total layer, salt; (e) surface layer, salt; and (f) subsurface layer, salt.

the basin). During convection, the mixed layer deepens into the lower layer thus driving a heat transport out of this layer, and a freshwater transport in. Associated and opposite trends occur in the surface layer.

This qualitative description also holds for the GSA years, when restratification trends persisted throughout the entire year, due to the confinement of the mixed layer to the upper $200 \mathrm{~m}$. The salinity data in the OWSB years are noisy, but the increase in salinity can be observed in Fig. 3. Note also the increase in amplitude of the surface layer's heat content variability during the GSA years (Figs. 5a and 5b).

\section{Lateral fluxes of heat and salt}

The changes in heat and salt content of any of the layers shown in Fig. 4 must result from a combination of heat and freshwater exchange with the atmosphere (surface fluxes), lateral mixing and advection with the surrounding ocean (lateral fluxes), and vertical mixing with the layers beneath and above. In this section, an effort is made to quantify the seasonality, interannual variability, and vertical structure of the lateral exchange of heat and salt between a water column (0$1300 \mathrm{~m}$ ), representing typical CLS conditions, and the surrounding ocean. It is assumed that vertical mixing is negligible except during active convection and, in general, that the vertical exchange beneath $1300 \mathrm{~m}$ is negligible. [This is only true if convection does not penetrate beyond this depth, which is acceptable for the periods under consideration except for winter 1971/72 (Lazier 1980; Lazier et al. 2002; Yashayaev 2004). For that year the calculation was repeated by extending the layer to $1500 \mathrm{~m}$, the approximate depth of convection for that year, but the change in the estimated fluxes was found to be negligible.]

As a first step in addressing the magnitude of the lateral fluxes, it is instructive to ask to what extent changes in the surface layer (which is permanently in contact with the atmosphere) can be attributed to the surface fluxes alone. For heat, it is apparent that the surface layer is strongly controlled by the surface fluxes. This is shown by comparing the estimated surface layer's heat content change from May to April 
obtained by applying the NCEP-NCAR surface heat fluxes, for the particular year, using that year's May value as the initial condition. Agreement between the observed and estimated is good until the winter/early spring convection period (Figs. 4c and 4d). Lilly et al. (2003) had presented a similar result for 1997 alone. The divergence between the two curves during the winter months is to be expected since strong vertical, convective mixing now extends beyond the surface layer. During the GSA years, when convection was limited to the surface layer, the two curves match throughout the winter months. For salinity, on the other hand, the surface $E-P$ flux of SM02 cannot explain much of the observed salinity change in the surface layer (Figs. $4 \mathrm{~g}$ and $4 h$ ). Note that this needed not be true a priori since the half a meter of freshwater added seasonally to the CLS, according to Lazier (1980) and Lazier et al. (2002), is of the same order of magnitude as the net $E-P$ estimated by SM02. The data, however, show that the seasonal freshening occurs more rapidly than can be explained by the $E-P$ flux of SM02, suggesting that it is dominated by the lateral exchange of cold, fresh surface waters.

Next, the lateral fluxes of heat over the total water column are estimated by subtracting the NCEP-NCAR surface heat fluxes from the observed heat content change for both records. Given the uncertainty in the surface $E-P$ flux, however, it does not seem appropriate to use the same approach for freshwater. Instead, for freshwater, what is considered is the flux implied by the observed changes in salt content (i.e., the lateral plus surface fluxes). This implied flux is expressed as the freshwater thickness (per meter squared) that would need to be added (negative implied $E-P$ flux) or removed (positive implied $E-P$ flux) to account for the observed salt content change.

To gain some insight into the vertical partitioning of these fluxes, the same calculation is repeated for the surface and lower layers during restratification alone. ${ }^{2}$ The assumption is that, during this time, exchange between the two layers is negligible. This means that from a knowledge of the surface fluxes, one can calculate the lateral heat flux for the surface layer as a residual. For freshwater, the implied surface $E-P$ flux is to be viewed as the sum of both the surface forcing plus the lateral fluxes. For the lower layer, any change observed during restratification is attributed to lateral exchange alone. For each year, the restratification period is identified as that period when the lower layer is warming. This heat

\footnotetext{
${ }^{2}$ During convection, when there occurs a vertical exchange between the two layers, the system reduces to two equations in three unknowns and cannot be solved without making some further assumption.
}

content definition is preferred to a "mixed layer" criterion since the profiles utilized in this study are monthly means and, for the floats, horizontally averaged, and do not capture well the evolving mixed layer. In most cases, the restratification period coincides with the period from May to December; for the GSA years, restratification lasts throughout the entire year.

The lateral heat fluxes and implied freshwater fluxes derived are used to address three questions: 1 ) Is there a seasonal cycle to these fluxes? 2) What is the mean transport of heat and freshwater through the central Labrador Sea, and how is it partitioned in the vertical? 3) How do the different terms, contributing to the net heat-freshwater transport, vary interannually?

\section{a. Mean seasonal cycle}

Mean seasonal cycles for the lateral heat fluxes, and the implied $E-P$ fluxes, are shown in Fig. 6. Overall, the sign and magnitude of these fluxes are similar for the two periods. One exception is the wintertime total lateral heat flux: the maximum convergence in the float record is absent from the OWSB (non GSA) record (Fig. 6a). The net impact of the lateral heat fluxes is to warm the $0-1300-\mathrm{m}$ water column. This convergence of heat, however, is principally due to the lower lateral fluxes since, at least during restratification, the surface fluxes act to cool the CLS (Figs. 6b and 6c). There is an indication that the lower convergence of heat is at a maximum at the start of restratification and decreases afterward (Fig. 6e).

Unlike for heat, the implied $E-P$ flux over the total layer changes sign throughout the seasonal cycle: freshening is observed during restratification but convergence of salt occurs during convection (Fig. 6d). This reversal occurs in both datasets and, thus, is likely a robust signal, notwithstanding the uncertainty of the OWSB salinity data. As was evident from Figs. 5g and $5 \mathrm{e}$, the implied freshwater flux differs considerably from the $E-P$ surface flux of SM02 (Fig. 6d), reflecting the importance of the lateral exchange with the surrounding ocean. This is consistent with the rapid postconvection freshening of the surface layer described in Lilly et al. (1999), and with the conclusion of Schmidt and Send (2005, manuscript submitted to J. Phys. Oceanogr.) that the freshwater gain due to lateral exchange accounts for approximately $80 \%$ of the total gain in the region. Also in agreement with the latter study, there is some evidence of the freshening occurring in two peaks: April-June and September-October. Both peaks are visible in the OWSB data but in the GSA years, the autumn peak is much more pronounced. In the float data, on the other hand, only the spring peak is found. Schmidt and Send (2005, manu- 
total
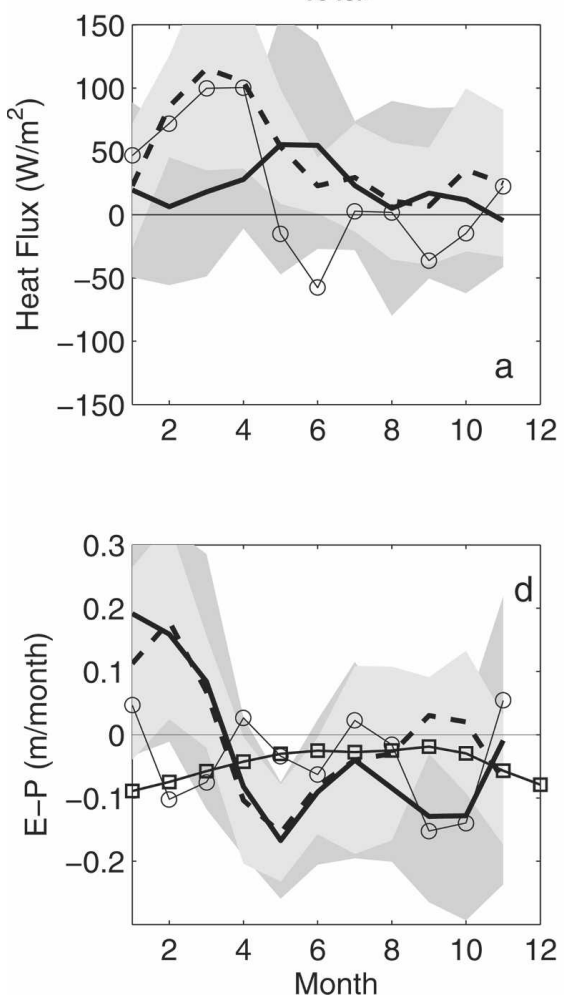

surface
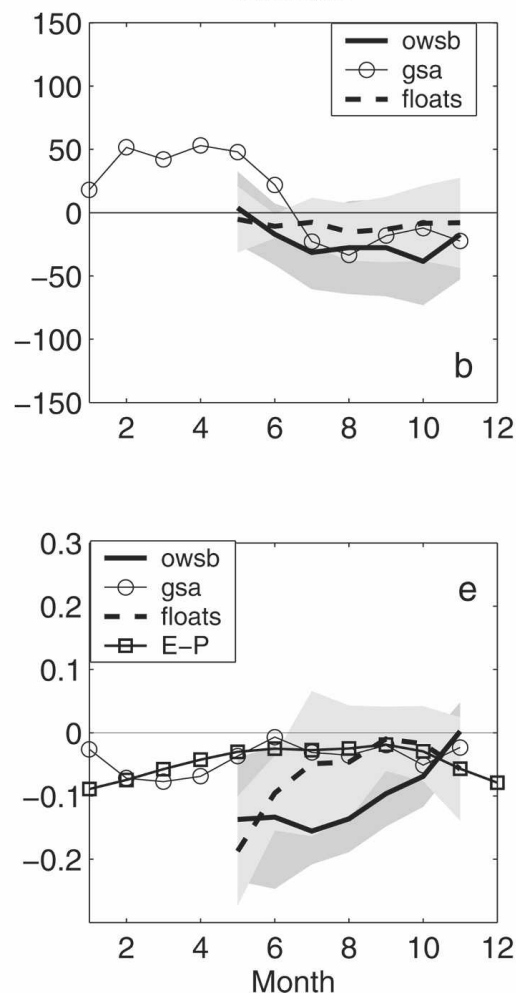

lower

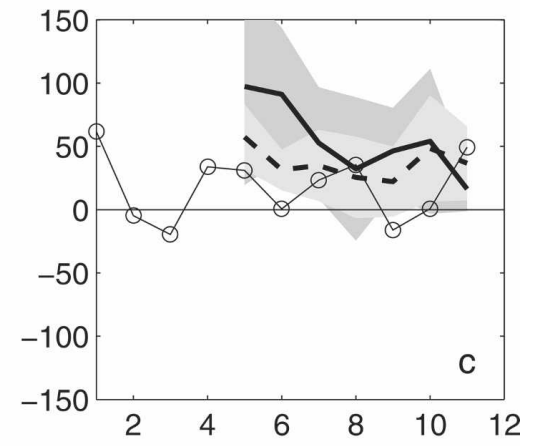

FIG. 6. (top) Mean lateral heat and (bottom) implied $E-P$ fluxes in the (left) total, (middle) surface, and (right) lower layers, for both datasets. Standard deviations for each dataset are shaded: (a) total, heat fluxes; (b) surface, heat fluxes; (c) lower, heat fluxes; (d) total, $E-P$ flux; (e) surface, $E-P$ flux; and (f) lower, $E-P$ flux. The climatological $E-P$ curve from Sathiyamoorthy and Moore (2002) is overlaid in (d) and (e).

script submitted to J. Phys. Oceanogr.) attribute the two peaks to separate pulses from the Labrador and West Greenland Currents, respectively. Given the absence of the earlier pulse in the GSA years, it is possible that this peak is tied to convection and, in particular, to the increased salinity of the surface waters during convection. The absence of the second peak in the float data is puzzling; it may be due to the larger area sampled by the floats or to problems with the floats' salinity calibration. The implied fluxes decay to the estimated surface $E-P$ flux values toward November, suggesting that the lateral freshwater exchange has considerably decreased by this time (Fig. 6e). This is consistent with the seasonal decrease in the freshwater transport by the Labrador and West Greenland Currents discussed in Schmidt and Send (2005, manuscript submitted to J. Phys. Oceanogr.).

Lateral fluxes during the GSA years are, in general, weaker. The implied $E-P$ flux for the total layer is much closer to the estimated $E-P$ flux, suggesting a limited impact of the lateral exchange of freshwater once freshwater had accumulated in the CLS. For heat, the reversal in sign of the lateral surface fluxes is likely to result from a wintertime reversal of the CLSboundary current temperature gradient at the surface as the CLS waters became considerably colder during the GSA years (see Fig. 6b and also Fig. 3).

\section{b. Net contribution}

The net contributions of the derived fluxes (annual for the total layer and during restratification for the surface/lower layers) are presented in Table 1. Broadly speaking the transport of heat through the system is the following. The convergence of heat due to the lateral fluxes is on the order of the mean annual heat loss (1 $\mathrm{GJ} \mathrm{m}^{-2}$, as one would expect). Much of this convergence occurs in the lower layer while the net impact of the surface lateral exchange is to cool. If the $0.9 \mathrm{GJ} \mathrm{m}^{-2}$ that is converged into the lower layer during the 8-month-long restratification is extended to the entire year, the resulting $1.3 \mathrm{GJ} \mathrm{m}^{-2}$ converged here are in excess of the annual heat loss. This is consistent with the idea that part of this heat is then mixed into the surface layer, during convection, and exported away from the region by the surface lateral fluxes.

Having proposed this general picture, one must note 
TABLE 1. Contributions of the lateral heat fluxes and implied $E-P$ flux. Values shown represent net annual (or annual average) for the 0-1300-m layer (total), and net during (or averaged over) the restratification period for the surface and lower layers. Values for the GSA years are estimated over the entire year. Shown are the monthly average $l$ and net contribution $L$, for both heat ( $H$ subscript) and freshwater $(F$ subscript). Also shown, for comparison, are the mean annual net heat $(Q)$ and freshwater $(E-P)$ loss due to surface fluxes for each period.

\begin{tabular}{|c|c|c|c|c|c|c|c|}
\hline Data & Layer & $l_{H}\left(\mathrm{~W} \mathrm{~m}^{-2}\right)$ & $L_{H}\left(\mathrm{GJ} \mathrm{m}^{-2}\right)$ & $Q\left(\mathrm{GJ} \mathrm{m}^{-2}\right)$ & $l_{F}\left(\mathrm{~m} \mathrm{month}{ }^{-1}\right)$ & $L_{F}(\mathrm{~m})$ & $E-P(\mathrm{~m})$ \\
\hline \multirow[t]{3}{*}{ OWSB } & Surface & $-21 \pm 35$ & $-0.38 \pm 0.17$ & $-1.05 \pm 0.6$ & $-0.1 \pm 0.08$ & $-0.66 \pm 0.31$ & \\
\hline & Lower & $53 \pm 53$ & $0.93 \pm 0.28$ & & $0.02 \pm 0.15$ & $0.11 \pm 0.33$ & \\
\hline & Total & $21 \pm 67$ & $0.61 \pm 0.46$ & & $-0.03 \pm 0.2$ & $-0.3 \pm 0.27$ & -0.55 \\
\hline \multirow[t]{3}{*}{ FLOAT } & Surface & $-6 \pm 26$ & $-0.13 \pm 0.22$ & $-0.80 \pm 0.4$ & $-0.08 \pm 0.1$ & $-0.63 \pm 0.11$ & \\
\hline & Lower & $43 \pm 35$ & $0.90 \pm 0.30$ & & $0.03 \pm 0.05$ & $0.21 \pm 0.1$ & \\
\hline & Total & $46 \pm 61$ & $1.34 \pm 0.84$ & & $0 \pm 0.14$ & $-0.07 \pm 0.32$ & $"$ \\
\hline \multirow[t]{3}{*}{ GSA } & Surface & $5 \pm 36$ & $0.12 \pm 0.45$ & $-0.3 \pm 0.06$ & $-0.04 \pm 0.07$ & $-0.35 \pm 0.22$ & \\
\hline & Lower & $18 \pm 50$ & $0.42 \pm 0.22$ & & $0 \pm 0.2$ & $0.02 \pm 0.42$ & \\
\hline & Total & $26 \pm 93$ & $0.58 \pm 0.29$ & & $-0.04 \pm 0.19$ & $-0.43 \pm 0.35$ & $"$ \\
\hline
\end{tabular}

that there are large differences in the heat transport estimates between the OWSB (non GSA) and the float years. Explicitly, the mean lateral heat fluxes $\left(l_{H}\right.$ in Table 1) over the $0-1300-\mathrm{m}$ water column during the OWSB period $\left(21 \mathrm{~W} \mathrm{~m}^{-2}\right)$ are approximately one-half of those estimated during the float period $\left(46 \mathrm{~W} \mathrm{~m}^{-2}\right)$. These numbers are supported by previous values obtained by Smith and Dobson (1984) $\left(29 \pm 22 \mathrm{~W} \mathrm{~m}^{-2}\right)$ and Ikeda (1987) $\left(25 \mathrm{~W} \mathrm{~m}^{-2}\right)$ using the same OWSB dataset, and by Lilly et al. (2003) for the 1990s. The latter study found that the mean lateral exchange (0$1400 \mathrm{~m}$, averaged over the entire year) varied between 16 and $85 \mathrm{~W} \mathrm{~m}^{-2}$ with a mean of $48 \pm 23 \mathrm{~W} \mathrm{~m}^{-2}$. This difference translates into a large difference in the net heat content change contributed by these fluxes $\left(L_{H}\right.$, Table 1). If compared with the net annual heat loss, this difference likely explains why the heat content of the water column is increasing during the float years. From the seasonal cycle for the lateral heat fluxes (Fig. 6a), it appears that this discrepancy is partly due to a wintertime convergence of heat during the float years. In part, however, it is also a result of the reduced cooling by the surface lateral fluxes during the float years relative to the OWSB years. Because of the crude $(200 \mathrm{~m})$ partitioning of these layers, it is difficult to understand whether this difference is due to actual changes in the roles of the cold, fresh surface waters or warm, salty Irminger Water. It may be, for example, that during the float years the lateral fluxes over the surface layer included more Irminger Water than during the OWSB years, which would result in reduced freshening and cooling by these fluxes.

In terms of salt, the large degree of uncertainty (and variability) makes it difficult to draw conclusions about the total annual budget. Yet, both datasets agree that approximately $0.6 \mathrm{~m}$ of freshwater accumulates in the region during restratification and that the lower-layer convergence of salt does not balance this amount (even if extended to the entire year). This implies that the excess freshwater must be somehow removed from the surface layer during the remainder of the year. From the seasonal cycle for the implied $E-P$ flux (Fig. 6d), one can infer that this removal occurs during the wintertime. One option is for it to be removed by excess evaporation. A second option is for it to be removed by the surface lateral fluxes, presumably during the winter.

Like the float years, the GSA years are characterized by a heat convergence that is in excess of the surface cooling, which is noticeably lower during these years, so that the water column warms (see Table 1 and also Fig. 4a). At the same time, it appears that these years are characterized by a different transport regime: the surface lateral fluxes act to warm the water column, while convergence of heat by the lower lateral fluxes is greatly reduced in magnitude. Consistent with reduced lateral salinity gradients at the surface, the surface convergence of freshwater, during the GSA years, is greatly reduced.

\section{c. Interannual variations}

The strong degree of interannual variability in the transport of heat and salt through the region is shown in Fig. 7. From Figs. 7a and 7b, it is evident that there is no direct (or even $1 \mathrm{yr}$ lagged) correlation between the amount of heat lost to the atmosphere and the amount of heat converged into the basin (as noted by the studies mentioned earlier). In terms of total heat transport, furthermore, the first $3 \mathrm{yr}$ in the float record stand out as years of anomalous heat convergence. Only a fraction of this extra heat is brought in during restratification, and appears in the form of a reduced cooling in the surface layer. The remainder, as shown in the seasonal analysis earlier, appears to be advected in during the wintertime. 

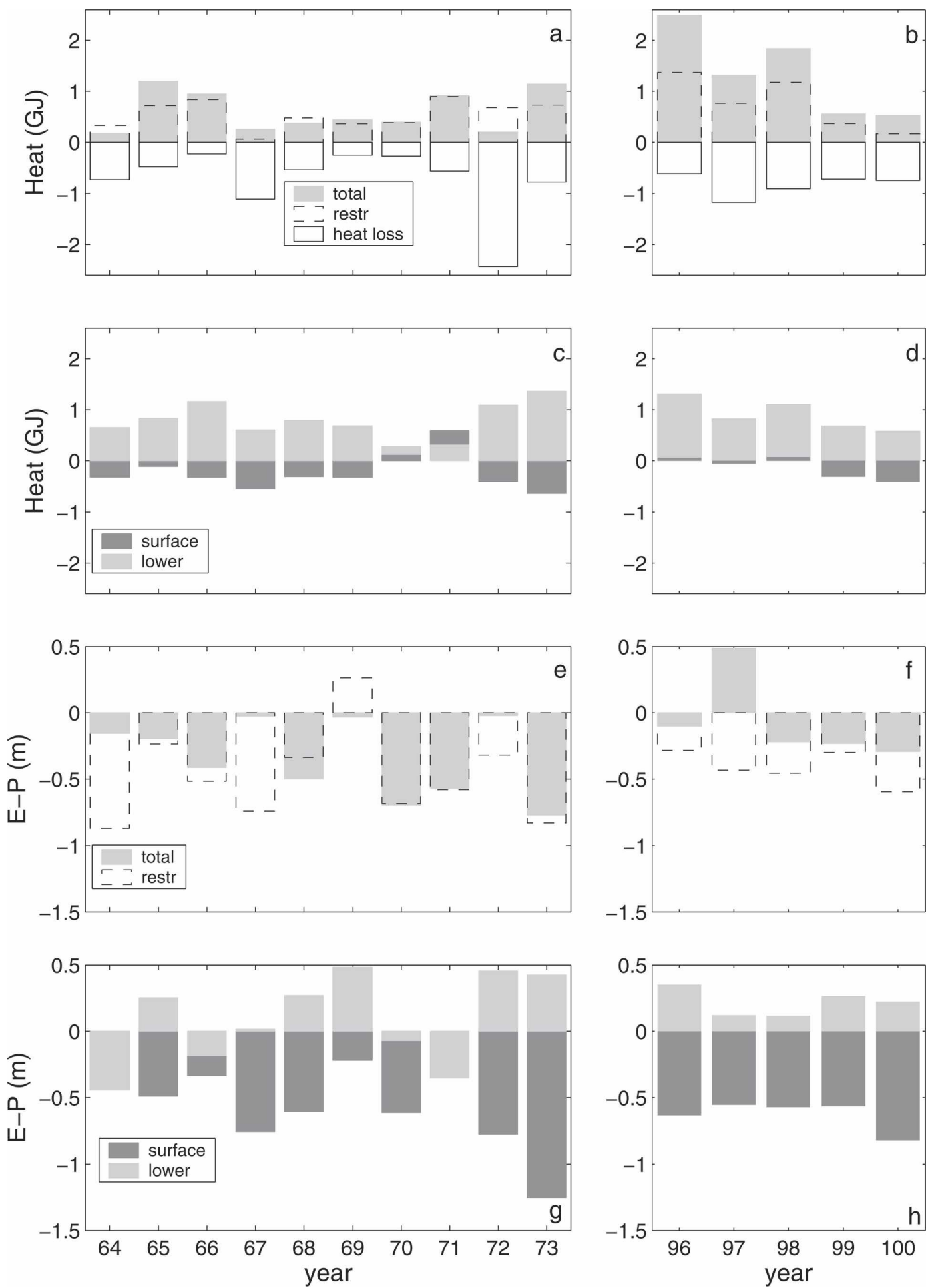

FIG. 7. (top two rows) Net heat and (bottom two rows) freshwater changes per year for the two datasets (left) OWSB and (right) floats. For heat, positive implies ocean gain. For freshwater, negative implies a freshwater gain. (a), (b) Annual heat content change due to the lateral fluxes in the 0-1300-m layer (total), in comparison with the net gain during restratification alone (restr). Also shown is the net annual heat loss to the atmosphere (heat loss). (c), (d) Net heat content change due to the surface and lower lateral fluxes during restratification alone. (e), (f) Net salt content change (expressed as $E-P$ flux) in the 0-1300-m layer (total) in comparison with the change during restratification alone. (g), (h) Salt content change (as $E-P$ flux) in the surface and lower layers, during restratification alone. 
Given that the float period was characterized by an overall lower net salinity, it is perhaps not surprising that the net accumulation of freshwater during these years is less than during the early OWSB years (prior to 1972). Like for heat, it appears that the differences arise from the wintertime fluxes, since restratification values are comparable for the two periods (Figs. 7e-h).

Among the float years, 1997 stands out because of its large freshwater divergence (effectively it is the only year showing a net increase in salt). Again, this appears to be due to a wintertime convergence of salt. These data thus suggest that at least some of the float years were characterized by an anomalous import of heat and salt during the wintertime. It is unclear at what depth this occurred. The reader is reminded, however, that the floats' salinities were corrected for drift using hydrographic data. Hence, it should not be surprising that for salinity one encounters the same interannual trends reflected by the hydrographic data (Yashayaev 2004). These results are consistent with the significant increase in heat content of the Labrador Sea, diagnosed from repeated hydrographic springtime sections that occurred from 1996 to 1997 (Lilly et al. 2003). In that study the authors suggest that this is associated with the increased number of warm, salty Irminger eddies (from instability of the boundary current off the west Greenland coast) that have been found in the central Labrador Sea at the same time.

Worth noting is the progressive change during the GSA years, as the surface lateral heat flux contribution progressively decreased then changed sign. Also, one can see a signature of the increased freshwater flux into the CLS in 1967 and 1968, which preceded the GSA period.

\section{Restratification dynamics}

In this study, the term restratification has been used to identify the evolution of properties of the CLS when it is not undergoing convection. For most years this identifies the postconvection months (MayDecember), whereas for the nonconvective years (such as the GSA years), restratification extends throughout the entire year. In agreement with the lateral fluxes discussed above, restratification tends to shift CLS properties toward boundary current properties and remove LSW. This is shown explicitly in Fig. 8, using data from two typical years (one year from each record). Restratification is principally characterized by a net warming of the water column, occurring mostly between 200 and $800 \mathrm{~m}$ (Figs. 8a and 8c). It is decoupled from the surface warming driven by solar insulation, which reverses sign in September while the subsurface waters continue to warm until December. Associated with the warming is the export of LSW from the CLS. This is visible in the downward motion of the isopycnal $\sigma_{d}=27.72 \mathrm{~kg} \mathrm{~m}^{-3}$ (see below), which represents the upper bound of LSW (Figs. 8a and 8c). The progression of CLS properties toward boundary current values is characterized by a rotation of $\theta-S$ properties toward the boundary current characteristics (Figs. $8 \mathrm{~b}$ and $8 \mathrm{~d}$ ). From both figures, and in agreement with the partitioning introduced here, the bulk of the warming occurs beneath $200 \mathrm{~m}$.

Restratification is likely driven by the combined action of eddies stirring properties within the Labrador Sea's interior and from the exchange with the boundary current. The interior redistribution of properties is consistent with the energetic eddy field that persists after convection in the numerical simulations of Legg and McWilliams (2001) and will act to remove any existing lateral gradient within the basin [due, e.g., to the lateral inhomogeneity of convection; Clarke and Gascard (1983) and Pickart et al. (2002)]. At the same time, boundary current instabilities, whether they be distributed around the basin (Spall 2004) or localized because of topography (Eden and Böning 2002; Katsman et al. 2004), must ultimately provide the mechanism that converges heat (and salt) into the Labrador Sea interior and removes the dense water formed. This boundary current-interior exchange is likely dominated by mesoscale eddies [found both in the modeling studies quoted above and also in the analysis of data from the CLS; Lilly et al. (1999, 2003)] and to be mostly adiabaticthat is, mixing properties, including thickness, along isopycnals (Gent and McWilliams 1990).

In a sense, one can think of convection as the process that creates and maintains a reservoir of LSW, thus maintaining strong lateral density gradients between the interior and boundary currents. (These gradients are apparent in the climatological hydrographic section shown in Fig. 9.) While the eddies (due to instabilities) can be considered to be the agents that are continuously attempting to suppress these gradients. A net result of this exchange is the export of LSW from the CLS and an import of less buoyant water (cold, fresh surface waters and subsurface Irminger Water). Given this scenario, one expects the lateral exchange to be controlled by the lateral isopycnal slope, which will govern the boundary current instability, as opposed to lateral gradients in the individual properties.

This hypothesis is tested in this section by investigating if the seasonal and interannual variabilities in the restratification rate can be related to changes in the interior-boundary current isopycnal gradient. Explicitly, the restratification rate is derived by diagnosing changes in LSW thickness. 
1973
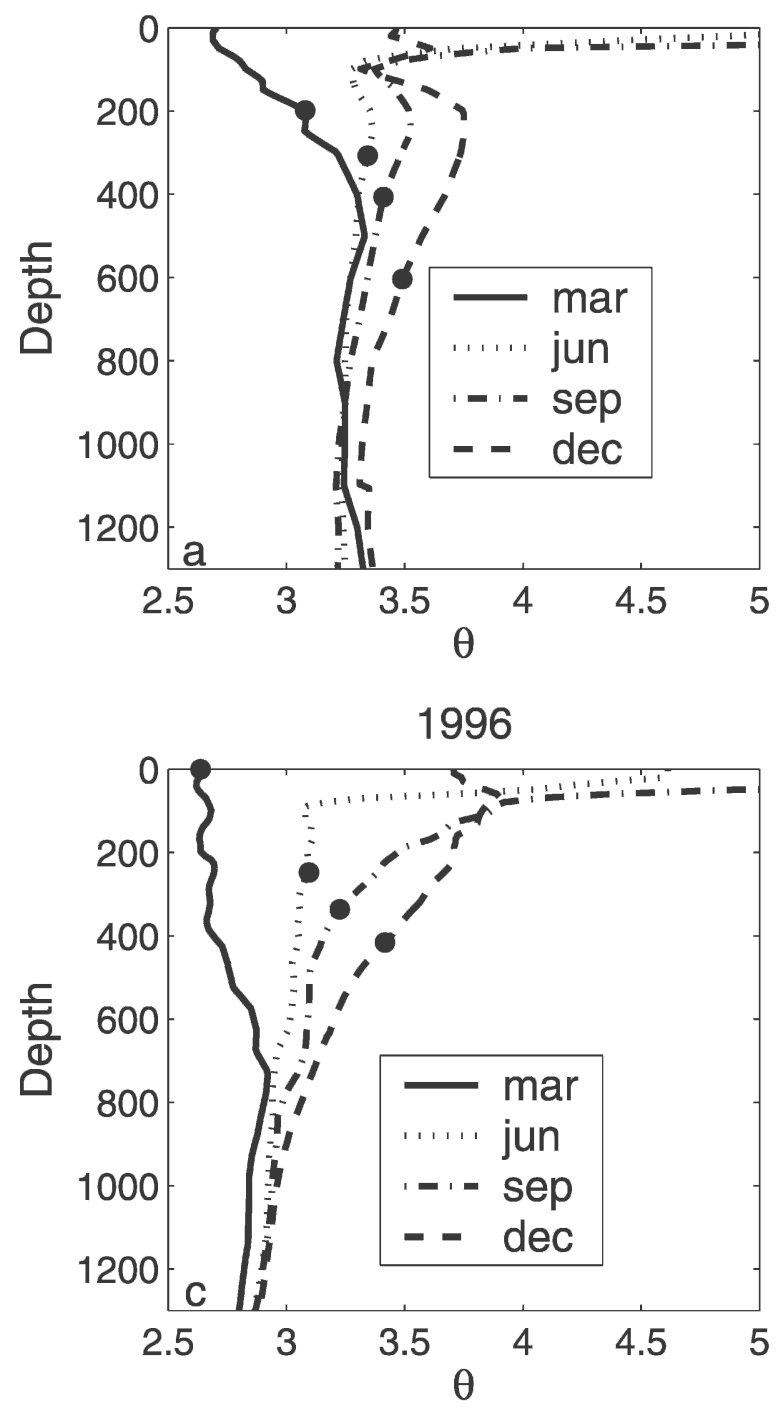

1973

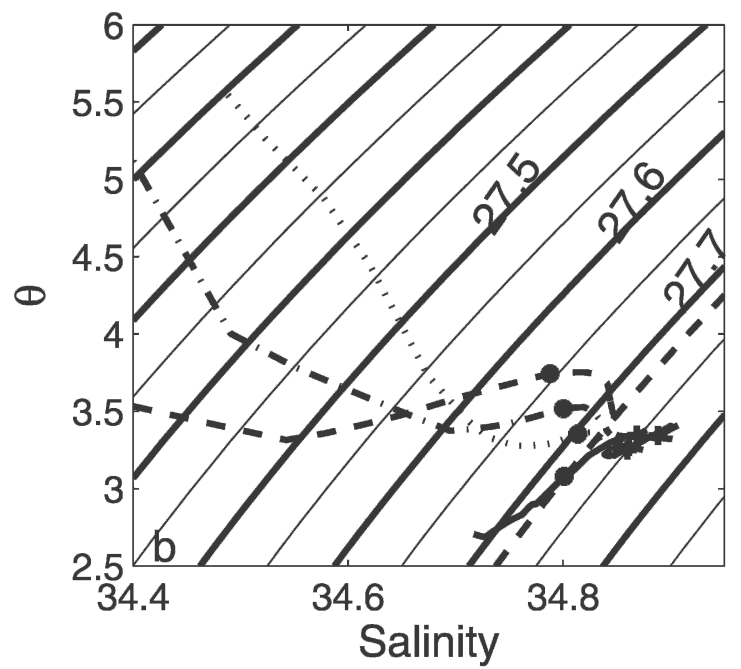

1996

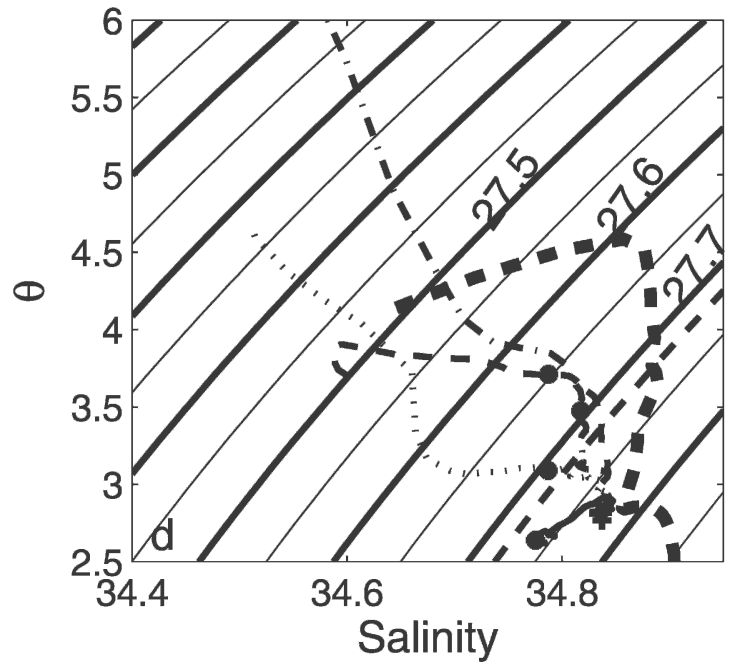

FIG. 8. (a) Seasonal $\theta$ profile evolution from 1973. Black circle indicates the depth of the $27.72 \mathrm{~kg} \mathrm{~m}^{-3}$ isopycnal. (b) Seasonal evolution of the $\theta-S$ diagram for 1973 . The $\sigma_{d}$ contour is shown as a dashed line. Black circles (crosses) indicate the $200-\mathrm{m}(1500 \mathrm{~m}$ ) depths. (c) Same as in (a) but for 1996. (d) Same as in (b) but for 1996. Overlaid as a thick dashed line are the $\theta-S$ properties of the West Greenland Slope Current from June 1996.

The latter is defined as inversely proportional to changes in the depth of an isopcynal that describes its uppermost limit, $\sigma_{\theta}=27.72$. This value is chosen as one that is lower than the density range of LSW produced in the basin but is denser than the Irminger Water in the boundary current. As shown in Fig. 9, $\sigma_{\theta}=27.72$ is found beneath the bulk of the warm water in the boundary current. From the same figure, one can see how this isopycnal is characteristic of the largest slope across the boundary current. In general, however, it should be made clear that the results presented are not overly sensitive to the exact value chosen for this "dividing isopycnal" ( $\sigma_{d}$ hereinafter) as long as it roughly separates LSW (typically ranging from 27.74 to 27.78) from the lighter, warmer Irminger Water [see also the $\theta-S$ diagram in Lilly et al. (1999) or Cuny et al. (2002)].

The vertical displacement of this isopycnal for both records is shown in Fig. 3 (bottom panel). If convection results in the formation of water denser than 27.72 [i.e., either upper or lower LSW; Kieke et al. (2006)], $\sigma_{d}$ rises toward the surface during the winter convective months. ${ }^{3}$ Following convection, $\sigma_{d}$ drops vertically as LSW is exported from the interior. A progressive de-

\footnotetext{
${ }^{3}$ In the monthly averaged data, one does not necessarily expect to capture its outcrop.
} 

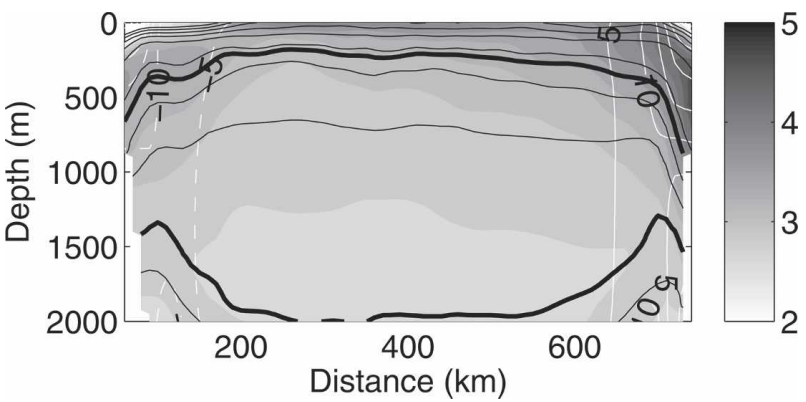

FIG. 9. Climatological AR7W $\theta$ late spring/early summer hydrographic section across the Labrador Sea, obtained by averaging occupations from 1990 to 1997 (courtesy of R. Pickart). Potential density contours are overlaid, with $\sigma_{\theta}=27.72$ and $27.78 \mathrm{~kg}$ $\mathrm{m}^{-3}$ shown in boldface, representing the upper and lower boundaries for Labrador Sea Water, respectively. Also overlaid is the velocity field ( $\mathrm{cm} \mathrm{s}^{-1}$; white) perpendicular to the section: positive values indicate poleward flow, and negative values indicate equatorward.

crease in LSW volume, during the early 1960s or throughout the late 1990s, is associated with a longterm deepening of the isopycnal. During the GSA years, when no LSW was produced, $\sigma_{d}$ moves downward at a fairly uniform rate with no apparent seasonality. Note also that 1965 and 1966 are years of weak convection, when only a small volume of water denser than 27.72 was formed, and that in 1999 no formation of water denser than 27.72 occurred according to the time series reconstructed from the floats.

\section{a. Seasonal thickness cycle}

The "sawtooth" pattern of convection and restratification in a typical convective year is shown in Fig. 10a. The average, seasonal displacement is $300 \mathrm{~m}$. Assuming

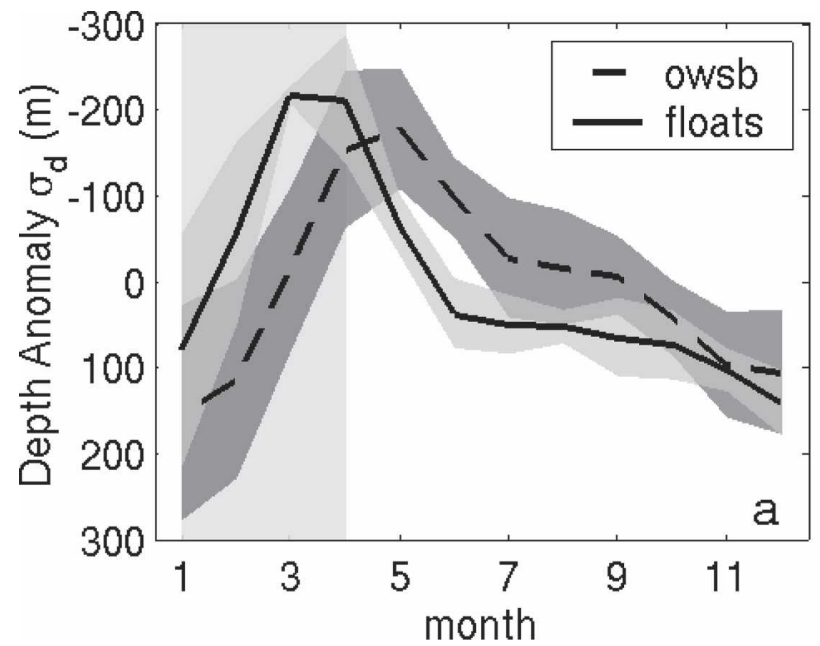

that this is representative of the entire Labrador Sea interior (of radius $250 \mathrm{~km}$ ) this change corresponds to an LSW formation rate of $1.2 \mathrm{~Sv}\left(\mathrm{~Sv} \equiv 10^{6} \mathrm{~m}^{3} \mathrm{~s}^{-1}\right)$, which is consistent with the estimates of Rhein et al. (2002) and Khatiwala et al. (2002). The GSA years, as well as 1999, are characterized by net downward displacement of about 100-150 m, with no apparent seasonality (Fig. 10b).

If one considers the displacement of $\sigma_{d}$ from the time when convection has ended (Fig. 11), two different restratification phases are evident. (For nonconvective years, displacement over the entire year is plotted; also 1968 and 1969 are omitted from this plot since they are characterized by a large intermonthly variability.) During the first phase, immediately following convection, $\sigma_{d}$ drops rapidly for 2-3 months. After, $\sigma_{d}$ continues dropping at a slower rate. More quantitatively, the initial rapid sinking rate is approximately $72 \mathrm{~m} \mathrm{month}^{-1}$, while the slower rate, obtained by imposing a linear fit (from 3 months after minimum isopycnal depth to December for the convective years and for the entire year for the nonconvective years), is $21 \mathrm{~m} \mathrm{month}^{-1}$. A previous estimate of the mean sinking during 1964-74, with no two-phase distinction, yielded a mean value of $30 \mathrm{~m} \mathrm{month}^{-1}$ (Khatiwala and Visbeck 2000). This pattern is consistent with the observations of Lilly et al. (1999) of the rapid decay of $\theta-S$ anomalies and variability on smaller scales $(100 \mathrm{~m}-10 \mathrm{~km})$, followed by a slow drift to warmer, more saline conditions at intermediate depths. The slower, uniform sinking rate is not only common to the latter portion of restratification of all convective years, but is similar to that observed throughout the entire year in nonconvective years.

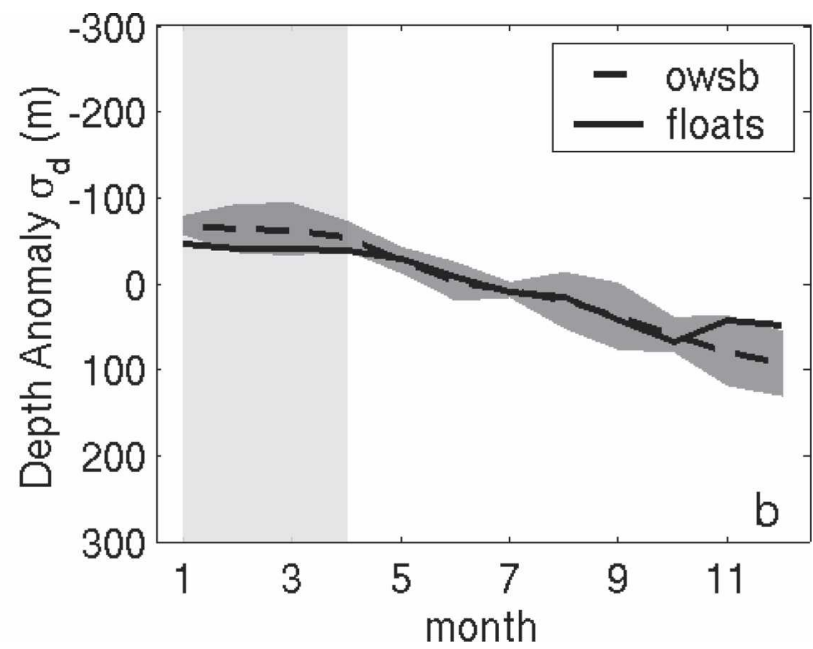

FIG. 10. Mean seasonal displacement of the $\sigma_{d}=27.72 \mathrm{~kg} \mathrm{~m}^{-3}$ isopycnal, with respect to the annual mean position, for (a) convective and (b) nonconvective years. 


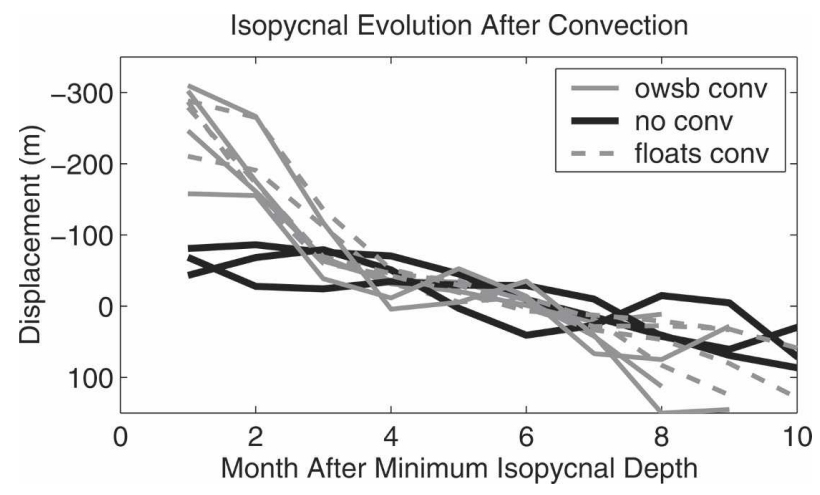

FIG. 11. Relative displacement (m) of $\sigma_{d}$ for all years. Convective years are plotted as a function of month after the minimum depth of $\sigma_{d}$.

It is proposed here that this two-phase adjustment is consistent with the mechanisms for lateral mixing proposed above: interior stirring by the vigorous post convective eddy field and exchange with the boundary current. Immediately following convection, the increased interior-boundary current isopycnal slope and the vigorous eddy field will quickly act to remove any interior inhomogeneities; see Figs. 12a and 12b.

The magnitude of the observed isopycnal displacement in the initial phase $[O(200 \mathrm{~m})]$ is what would be expected from an internal redistribution. Let $R_{b}$ be the basin's radius, $R_{c}$ the radius over which convection has occurred, and $h_{d}$ the depth of $\sigma_{d}$ outside of the convection region (in the convection region this isopycnal is at the surface). A rapid flattening of the isopycnal gradient, within the basin, will result in a net drop of this isopycnal (in the convective region) of $\Delta h$, which, from volume conservation, is given by

$$
\Delta h=\frac{h_{d} R_{c}^{2}}{R_{b}^{2}} .
$$

Using typical Labrador Sea values $\left(R_{b}=250 \mathrm{~km}, R_{c}\right.$ $=150 \mathrm{~km}$, and $\left.h_{d}=600 \mathrm{~m}\right), \Delta h$ is estimated to be around $210 \mathrm{~m}$, similar to that observed. Beyond this initially rapid phase, the slower exchange between the interior and the boundary current continues throughout the entire year; see Figs. 12b and 12c. Support for the notion that this slower phase is due to the mean "background" lateral isopycnal gradient is provided by its persistence during nonconvective years (Fig. 11), when it cannot be attributed to that year's convective activity.

\section{b. Interannual variability of thickness}

If the restratification of the Labrador Sea interior results from instabilities trying to "flatten" the lateral isopycnal gradient between the interior and the bound-
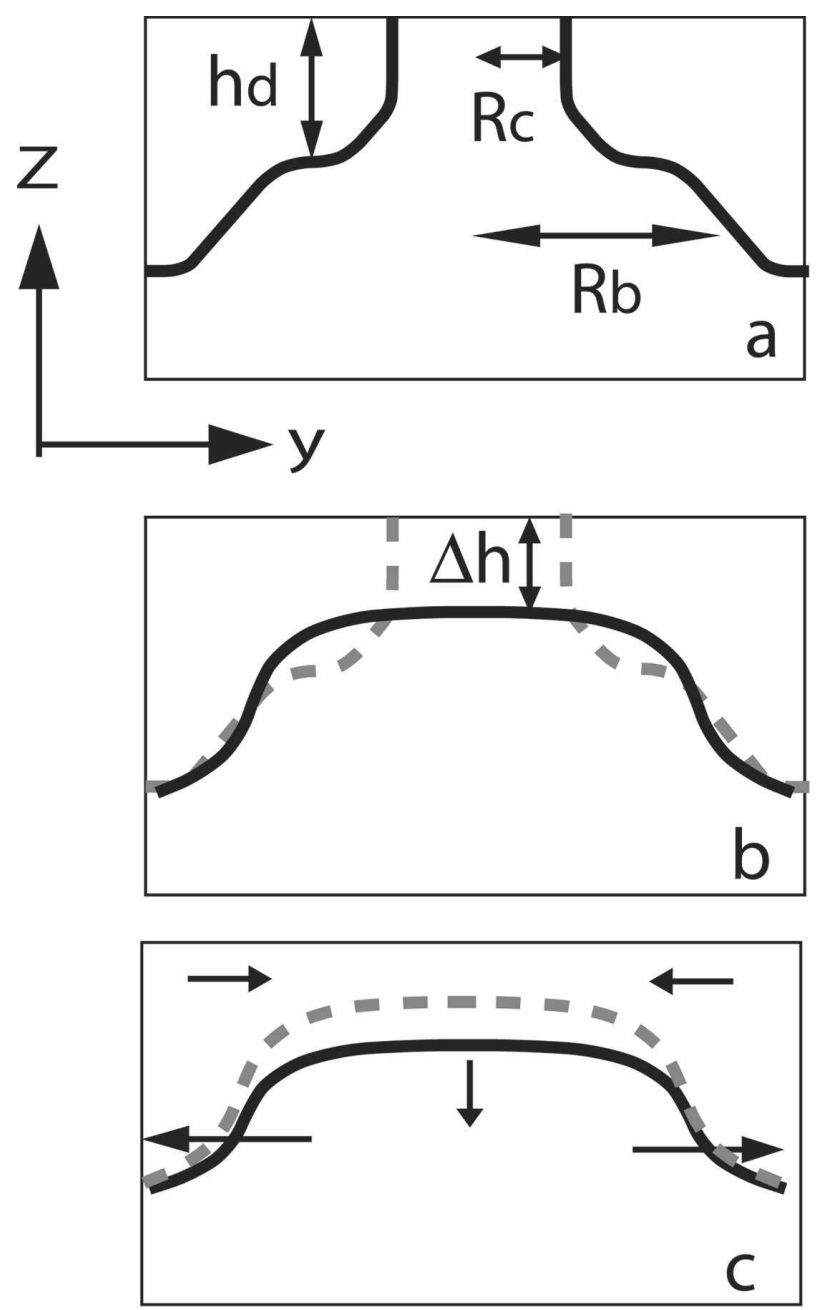

FIG. 12. Schematic representation of the evolution of $\sigma_{d}$ in a vertical section across the Labrador Sea: (a) convection has occurred over a limited portion of the basin, (b) initial rapid adjustment, and (c) slower adjustment (dashed line shows position of $\sigma_{d}$ from the previous stage, and arrows indicate exchange with the boundary current and downward displacement of $\sigma_{d}$ ).

ary current, one would expect to see a correlation between the rate of restratification and the magnitude of the isopycnal gradient. Because density is controlled by both temperature and salinity, this may explain why attempts to correlate interannual variations in the convergence of heat with the history of convection fail. Consider, for example, two years in which the same amount of LSW is formed with different, but compensating, temperature-salinity properties, and assume that the boundary current properties and structure are the same for both years. The restratification rate in terms of buoyancy will be the same in both years, since the isopycnal gradients are the same, but the convergence of heat will differ: the year with colder LSW will 
be characterized by a larger convergence of heat than the year with warmer LSW.

The relation between the rate of restratification and the isopycnal gradient between the interior and the boundary current is tested as follows. It is assumed that the CLS is a cylinder surrounded by a circular boundary current. Because of convection within the basin, the LSW layer is thicker in the interior than in the boundary current (Fig. 9). Instabilities will act to decrease this gradient by resulting in a convergence of light fluid into the basin and an export of LSW. If one assumes that the bulk of the isopycnal gradient occurs between LSW (in the interior) and Irminger Water (in the boundary current), in agreement with the hydrographic section shown in Fig. 9, one can approximate the system with a two-layer system and express conservation of mass in the interior as

$$
\Delta \rho \frac{d h_{i}}{d t}+\frac{1}{A} \oint_{P} \int_{H} v^{\prime} \rho^{\prime} d l d z=\frac{\rho_{0}}{g} Q_{b},
$$

where $Q_{b}$ is the surface buoyancy loss (assumed uniform over the interior), $\Delta_{\rho}$ is the density difference between LSW and Irminger Water, $A$ is the area of the interior, $P$ is the perimeter, $H$ is the water column thickness, $h_{i}$ is the thickness of LSW in the interior, and $v^{\prime} \rho^{\prime}$ are the eddy fluxes of mass representing the interior-boundary current exchange. Following Spall and Chapman (1998 and references therein), the eddy fluxes can be parameterized in terms of $h_{i}-h_{\mathrm{bc}}$, the LSW thickness difference between the interior and the boundary current, to yield

$$
v^{\prime} \rho^{\prime}=\frac{2 c g^{\prime}}{f L^{2}}\left(h_{i}-h_{\mathrm{bc}}\right),
$$

where $g^{\prime}=g \Delta \rho / \rho_{0}$ is the reduced gravity, $c$ is an efficiency parameter, $L$ is the boundary current width, and $h_{\mathrm{bc}}$ is the thickness of LSW in the boundary current. During restratification, when $Q_{b}$ is zero and convection is shut off, having substituted for the eddy fluxes, and assuming that changes in the boundary current around the perimeter are small ( $h_{\mathrm{bc}} \approx$ const), (1) reduces to

$$
\frac{d h_{i}}{d t} \approx-\frac{2 g^{\prime} c P}{f L^{2} A}\left(h_{i}-h_{\mathrm{bc}}\right)^{2} .
$$

This relation simply states that the export of LSW (expressed via the decrease in $h_{i}$ ) is due to the interiorboundary current exchange, and that rate of export is proportional to the square of the thickness gradient between the interior and the boundary current. A more detailed description of how this model applies to the Labrador Sea can be found in Straneo (2005).
One can then proceed to test the validity of the relation in (3) as follows. It is assumed, for simplicity, that the restratification rate is approximately uniform during the restratification period. To first order, then, the rate of shrinking of LSW should vary with the square of the initial thickness difference between the interior and boundary current:

$$
\frac{\Delta h_{i}}{\Delta t_{R}} \propto\left(h_{i}^{0}-h_{\mathrm{bc}}^{0}\right)^{2}
$$

where $\Delta h_{i}$ is the thickness change during restratification and $\Delta t_{R}$ is the duration of the restratification period. Effectively, this states that when the volume of LSW is large, restratification will occur at a faster rate relative to when it is small, and that the rate change varies like the square of the thickness difference. For each year, a mean restratification rate is computed by dividing the net thinning of LSW during restratification (the net downward displacement of $\sigma_{d}$ ) by the restratification time interval. This is plotted against the initial thickness difference between the interior and boundary current $\left(h_{i}{ }^{0}-h_{\mathrm{bc}}{ }^{0}\right)$, assumed to be proportional to the difference in the depth of $\sigma_{d}$ between the two regions. In the boundary current, $\sigma_{d}$ is assumed to be fixed at $700 \mathrm{~m}$, a value inferred from the climatological hydrographic section across the basin shown in Fig. 9. The comparison between data and theory is shown in Fig. 13a. The predicted quadratic relationship is found to fit well the observed interannual variability in the restratification rate. Note that all years are plotted here, including the GSA years when convection did not occur.

These results show, then, that the rate of export of LSW (and import of lighter water) depends on the interior-boundary current thickness gradient. Because of the interplay of heat and salt in defining density, however, there is no equivalently simple model for how much heat or salt are brought into the Labrador Sea during restratification. Indeed, attempts to find a correlation between the amount of restratification and the amount of heat converged fail-suggesting that the relation is a more complex one. It is found, however, that the amount of heat converged into the basin is indeed inversely correlated with the temperature of the lower layer (which mostly represents that of LSW; see Fig. 13b). Thus, years when convection produces a colder vintage of LSW (such as 1972, or the beginning of the float years) are associated with a larger transport of heat into the basin by the lateral fluxes than warm LSW years.

Beyond the interplay of temperature and salinity, other factors may contribute to the difficulty of predicting how much heat is annually converged into the basin. 

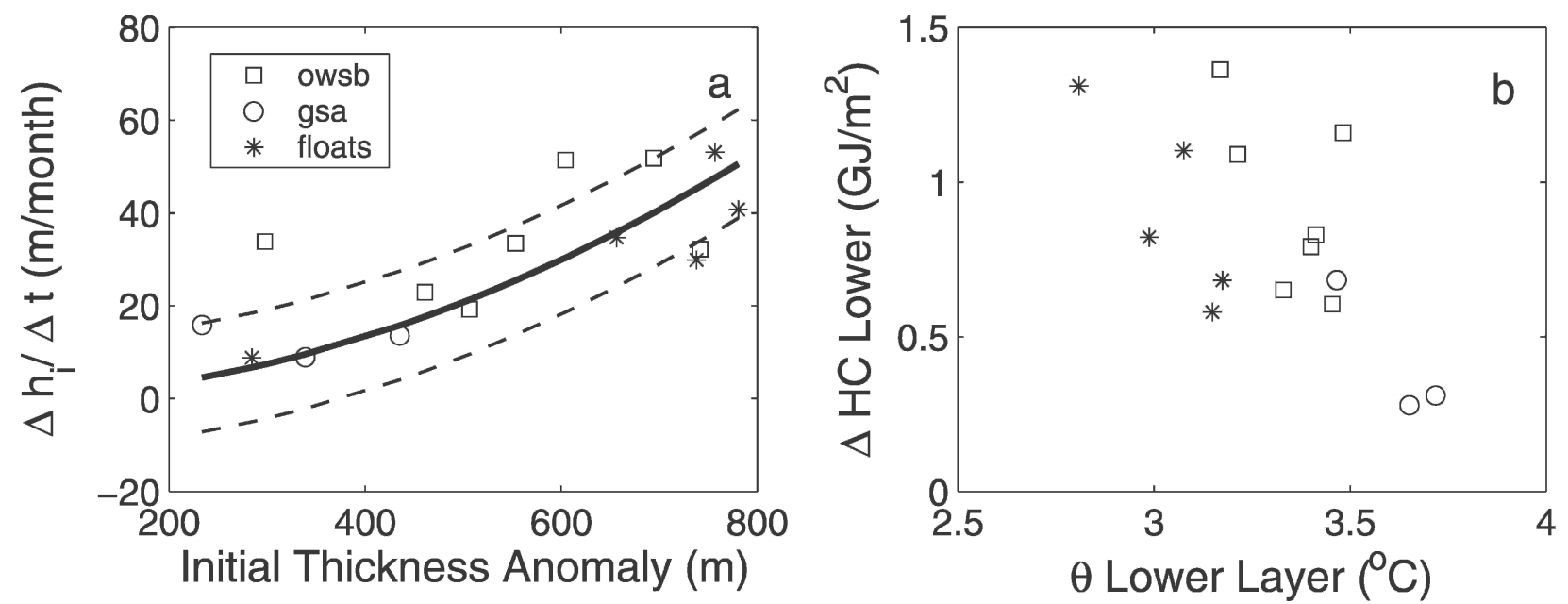

FIG. 13. (a) Restratification rate vs Labrador Sea Water thickness difference, between the CLS and the boundary current, at the start of restratification, for all years. Overlaid is the model prediction (i.e., a quadratic fit); plus and minus one standard deviation is shown as dashed lines. (b) Net heat content change in the lower layer during restratification vs mean temperature of the lower layer at the start of restratification.

Explicitly, it could be that some of the variability is due to factors that are independent of conditions in the CLS and of the amount of LSW present. One can imagine, for example, that variations in the interior-boundary current exchange can result from variations in the stability of the boundary currents due to nonlocal processes, such as an increased transport due to large-scale or remote wind forcing anomalies. Potentially indicative of such external factors is the increased production of warm, salty Irminger Eddies observed by Lilly et al. (2003) in 1997.

Last, attempts to relate variations in the implied lateral $E-P$ flux to the end-of-convection conditions in the Labrador Sea or, in general, to the restratification rate, did not produce statistically significant results. This is to be expected given the partial failure of the same calculations for heat and given that salinity is a noisier field (especially in the OWSB data). Furthermore, the salinity balance is likely strongly controlled by the amounts of freshwater carried by the West Greenland and Labrador Currents, which are likely to undergo large interannual variations as exemplified by the transit of the GSA around the subpolar gyre.

\section{Summary and discussion}

Historical hydrographic data from the Ocean Weather Station Bravo, from 1964 to 1974, and modern data derived from profiling floats, from 1996 to 2000, have been analyzed in an effort to diagnose the seasonal and interannual variability in the transport of heat and salt through, and in the export of LSW from, the Labrador Sea's interior. The comparison of the two periods is particularly interesting since the CLS is known to have considerably freshened and cooled from the mid-1960s to the late 1990s. Also, the earlier dataset contains the only record of a period when deep/ intermediate convection was shut down (from 1969 to 1972, the GSA years), offering a unique snapshot of how the flow of heat and freshwater through the region may be different during such a period.

The general picture emerging from this study is as follows. The CLS experiences a mean annual heat loss on the order of $1 \mathrm{GJ} \mathrm{m}^{-2}$ that, combined with the limited mean oceanic circulation through this region, drives deep convection and maintains a reservoir of convectively formed LSW. The mean formation rate of LSW is estimated to be $1.2 \mathrm{~Sv}$, deduced from the mean annual thickening and thinning of the LSW layer and extrapolating over the sea's interior. Convection occurs in the winter and is characterized by a cooling and freshening of the subsurface waters producing a net flux of heat and salt into the surface layers. Outside of the convection period, changes in the central Labrador Sea reflect the vigorous lateral exchange with water masses from the boundary current-as exemplified by the shift of properties toward boundary current characteristics. This lateral exchange results in restratifying the interior region: buoyant water is converged and dense LSW is removed.

The lateral exchange, presumably due to mesoscale eddies, occurs at a rapid rate during the first few months following convection, but persists at a slower rate throughout the entire year. Because the data in this 
study are based on are concentrated in the region of deepest convection, it is suggested that the initial rapid phase is, in part, due to a lateral homogenization within the basin driven by the energetic turbulent field leftover after convection. The slower phase, on the other hand, is likely to reflect the continuous exchange with the boundary currents. This scenario is consistent with the fact that a slow, steady restratification is observed throughout the year in years when convection did not occur. This supports the notion that restratification is not associated with the immediate convective process itself but rather with the mean horizontal density gradients, between the interior and the boundary currents, maintained by the repeated and integrated occurrence of convection.

The lateral fluxes have a vertical structure that resembles that of the boundary currents: cold, freshwater overlying warm, salty Irminger Water. The net heat loss to the atmosphere of approximately $1 \mathrm{GJ} \mathrm{m}^{-2}$ is balanced, and exceeded, by a subsurface convergence of heat (roughly below $200 \mathrm{~m}$ ) attributed to the import of Irminger Water. The excess heat is balanced by a surface divergence of heat due to mixing with the cold, fresh surface waters present in the boundary currents. Over half a meter of freshwater accumulates in the region during the spring/summer months. This convergence is attributed to lateral exchange at the surface, since its seasonality is offset from that of the most recent estimates of the surface $E-P$ fluxes. A fraction of this freshwater is mixed downward during convection, but the subsurface divergence of freshwater is not large enough to balance the annual gain. Hence, it appears that some of this freshwater must be removed from the surface layer in the winter, either by net evaporation or lateral mixing with neighboring saltier waters. While convection was shut down, during the GSA years, the interior-boundary current exchange persisted, albeit at a reduced rate. The lower layer became warmer and saltier and LSW was slowly exported with no apparent seasonality. In the surface layer, the accumulation of freshwater resulted in a reduced freshwater exchange and in a reversal of the surface, lateral heat flux during the winter (as the CLS surface waters became anomalously cold).

While the general characteristics of the seasonal cycle of convection and restratification are robust, there is considerable interannual variability in the extent of convection and in the magnitude of the lateral fluxes of the different properties. Given that the restratification driven by these fluxes sets the stage for the coming year's likelihood of convection and, in general, is linked to the export of LSW, one important issue is to understand what governs this interannual variability. Earlier attempts to relate interannual changes in the amount of heat converged by the lateral fluxes into the basin to variations in the net atmospheric heat loss or to the history of convection had previously failed. A different approach is taken in this study. Given that restratification is ultimately governed by the exchange between the CLS and the boundary current, dynamically one expects it to vary as function of the lateral density gradients. Using a simple model, where the interior-boundary current exchange is parameterized, it is argued that the restratification rate (or equivalently that the amount of LSW exported) must vary with the square of the lateral density (or thickness) gradient. This prediction is tested against the data analyzed in this study and is found to fit the data well. The good agreement, furthermore, is not limited to convective years but also encompasses years when convection did not occur. Explicitly, this means that years when a large volume of LSW is present will restratify at a faster rate than years when only a small volume of LSW is present.

This dependence on density gradients, as opposed to property gradients, likely explains why one cannot obtain a similarly simple relation for heat and salt. At the same time, it is shown that some of the interannual variability in the convergence of heat can be attributed to changes in the temperature of the convectively formed LSW: cold (warm) LSW periods are associated with a large (low) convergence of heat. The remaining variability, however, appears to be uncorrelated with conditions within the Labrador Sea-suggesting it is a response to external factors. In particular, the float period seems to be characterized by greater heat convergence than the OWSB period and, according to this analysis, some of this extra heat is brought into the region during the wintertime. During 1997, the anomaly extended to salt as well. It has been suggested that this is due to changes in the number of warm, salty anticyclones that detach from the boundary current off west Greenland.

A number of basic, unanswered questions emerge from this analysis. First, while it seems that the basic heat budget of the region mostly balances, this is less true for freshwater. The wintertime removal of freshwater still needs to be explained and, in general, we still need to understand how the lateral exchange of freshwater occurs, over what depths, and what it is governed by. One may ask, for example, if the instabilities and eddies that act to advect warm, salty subsurface Irminger Water into the interior are also advecting surface freshwater at the same time. Last, there remains the issue of how representative of the entire Labrador Sea interior these two datasets really are. 
Ultimately, this study can be considered a test case for the use of profiling float data in the construction of property time series for a limited region. Of the many regions where this may be attempted, the Labrador Sea seems particularly ideal given the large number of floats deployed there and given its relative lateral homogeneity. Through a comparison with the historical hydrographic data, it is shown that the two periods were very similar in terms of the seasonal cycle and, in general, of how the system works. This supports the float data's ability to capture both seasonal and interannual variations.

Acknowledgments. I thank the following people for making their data available and for many interesting discussions: B. Owens, K. Lavender, S. Sathiyamoorthy, G. W. K. Moore, T. Kuhlbrodt, I. Yashayaev and R. Pickart. Additionally, I am indebted to J. Lilly, M. Spall, S. Lentz, and J. Lazier for many constructive suggestions. This work was supported by NSF Grant OCE 02-40978, the John E. and Anne W. Sawyer Endowed Fund, and the Grayce B. Kerr Fund.

\section{APPENDIX}

\section{Constructing a Time Series from P-ALACE Float Profiles}

From 1996 to 2000, roughly 1000 profiles were collected by P-ALACE floats in the CLS (see Fig. A1). Most profiles extended to $1300 \mathrm{~m}$ and some to $1500 \mathrm{~m}$. Conductivity sensors mounted on the floats are known to drift, and since no postdeployment calibration is possible, somehow one must correct for this drift. To give an idea of the magnitude of the drift, the uncorrected salinity profiles yield a range of salinities in the LSW interval (i.e., around $1200 \mathrm{~m}$ ) from 34.67 to 35.11 (as compared with an observed mean value of 34.85 ). This range is much larger than the variability at depth, but less than the amplitude of the seasonal cycle at the surface. Several attempts to systematically infer the drift were made but none was very successful (B. Owens 2004, personal communication). At the same time, the profiles showed realistic features except for a large offset in salinity space. In the end, I decided to correct each profile by offsetting its salinity so that at depth (where the seasonal cycle in salinity is small) it matched that observed by hydrography. More precisely, it was imposed that the average salinity between 1100 and $1300 \mathrm{~m}$ match that observed during that same year from hydrographic measurements, generally taken in the spring. The same offset was applied to the entire water column. The hydrographic time series used for

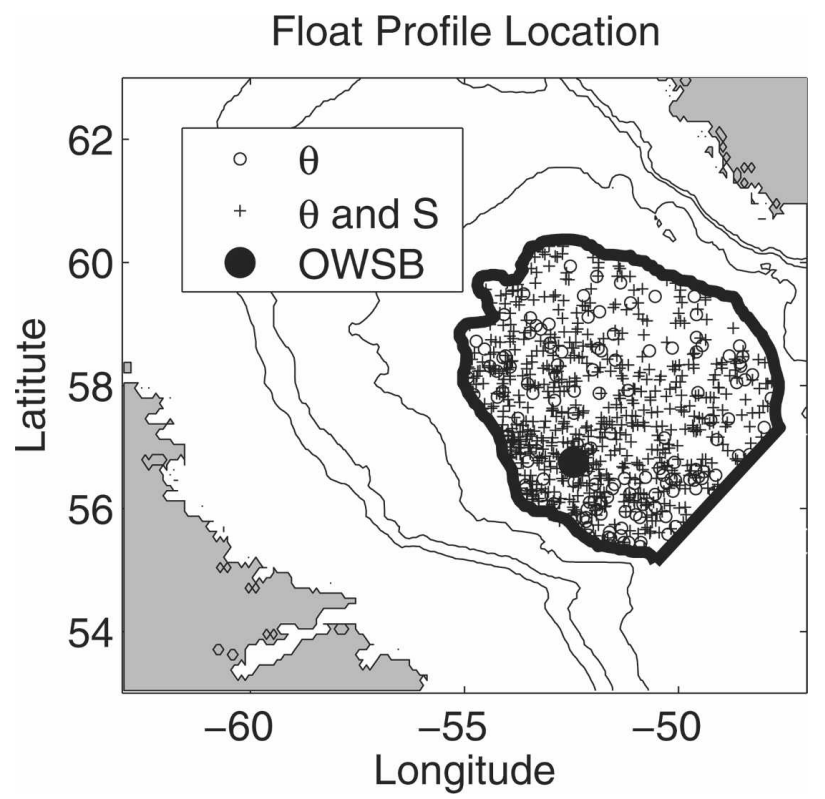

FIG. A1. Float profiles and OWSB location. The thick line indicates the CLS as defined by the 3300-m isobath and closed by a straight line at the southeastern end. Profile locations indicate whether only the temperature data (open circle) or both temperature and salinity (open circle plus cross) were used. The large circle indicates the location of the OWSB. Isobaths shown are 1000, 2000, and $3000 \mathrm{~m}$.

the float calibration was constructed by I. Yashayaev and is described, for example, in Dickson et al. (2002). It was obtained by horizontally averaging all profiles in the Labrador Sea interior, most of which were taken during late spring/summer surveys. The 1100-1300-m depth interval is chosen as one deep enough for the seasonal variation in salinity to be small and yet within the range of the majority of the float profiles. Those salinity profiles that did not extend to at least $1100 \mathrm{~m}$ were discarded since it would be difficult to calibrate them. If a profile extended beyond $1100 \mathrm{~m}$ but ended prior to $1300 \mathrm{~m}$, the calibration applied was corrected to be that over the covered portion of the 1100-1300-m interval. This type of calibration will clearly force the float data to have the same interannual character as the hydrographic data, and, indeed, the float data show the same freshening as observed in the hydrography. For much of the analysis conducted in this study, however, what is of interest are the variations within one seasonal cycle; hence, the calibration seems appropriate. And, as discussed in the text, the float data do indeed capture the subsurface seasonal increase in salinity. At the same time, there is a degree of uncertainty in these data, and any conclusion drawn must be interpreted with caution.

All temperature profiles (even those shallower than $1100 \mathrm{~m}$ ) were kept. To ensure independence of the in- 
Float Profiles

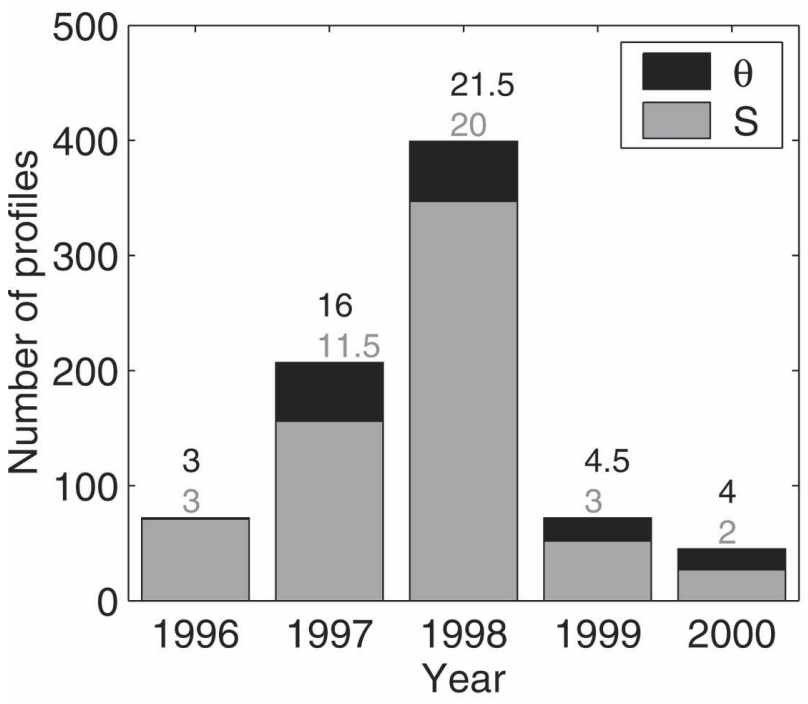

Profile Distribution

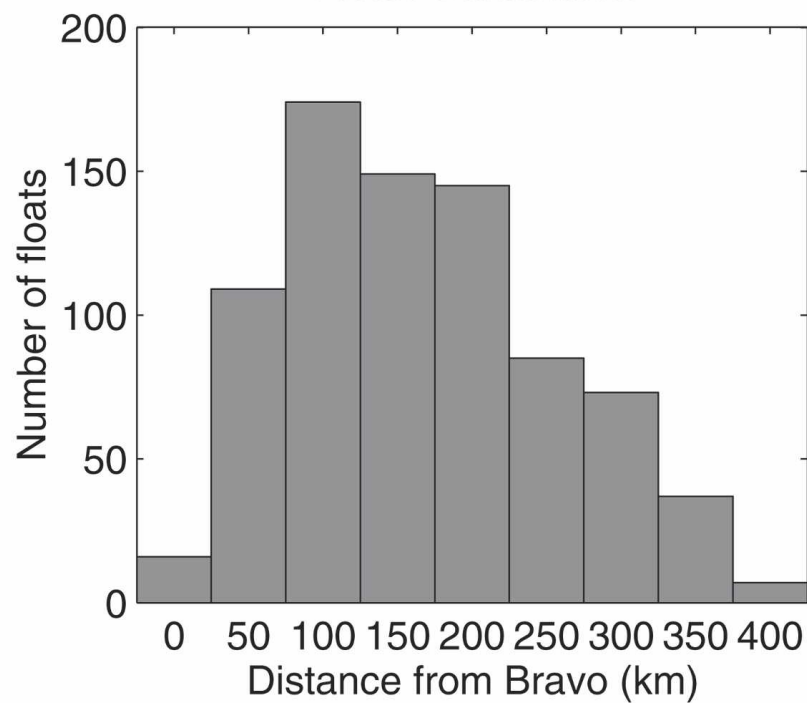

FIG. A2. (left) Histogram of the total number of salinity (gray) and temperature (black) profiles within each year. The number above the bar indicates the median number of profiles per property for that particular year. (right) Histogram showing the mean profiles distance from the OWSB.

dividual profiles, float profiles taken within $10 \mathrm{~km}$ of each other and less than 10 days apart were averaged into a single profile. Profiles presenting unphysical spikes were discarded.

Last, it appeared that several floats were caught in some of the warm eddies shed off the Greenland coast [these eddies are easy to identify because of their warm, salty signature; Lilly et al. (2003)]. In principle, if the floats' densities were high enough to sample the entire CLS uniformly, one could retain the eddy profiles and hence obtain, through horizontal or isopycnal averaging, the mean conditions of the CLS if all the waters had been horizontally (or isopycnally mixed). In practice, however, the uneven sampling implies that during some months no eddies were sampled and during some months the eddies dominated the signal. ${ }^{4}$ The number of eddies sampled was too few to be able to resolve the seasonal variability detected by Lilly et al. (2003) or Prater (2002) in the number of eddies present in the CLS. Nor did the different years show any systematic pattern-again most likely due to the poor sampling. Since the profiles within the eddies would bias properties toward "eddy waters," which are distinct from the typical "interior" properties of the CLS, all eddy profiles were omitted from the monthly mean. Such a choice is also in agreement with the fact that, until an

\footnotetext{
${ }^{4}$ Once caught in an eddy, a float is likely to remain trapped within it for several months.
}

eddy is destroyed (e.g., by wintertime convection, interaction with topography, or spindown), its waters are effectively isolated from the interior waters.

The final analysis was based on 795 temperature profiles and 653 salinity profiles whose spatial distribution is shown in Fig. A1 and temporal distribution shown in Fig. A2. While the CLS covers a large area, the floats did not sample the basin homogeneously but tended to be mostly concentrated within $200 \mathrm{~km}$ of the Bravo location ( $75 \%$ of the floats; see Fig. A2). This is partly due to the fact that many of the floats were originally launched in this region and partly to the fact that this is a fairly quiescent region where floats (and eddies) can remain for relatively long periods of time [see Lilly et al. (2003), e.g., for a description of the eddies persisting at the site of the Bravo mooring].

Monthly mean time series for temperature and salinity were generated by horizontally averaging all profiles within a given month. The horizontal averaging is justified given that isopycnals within the CLS are mostly flat (see, e.g., Pickart et al. 2002). A 10-m mixed layer was imposed on all monthly averaged profiles to remove some of the noise in the surface values (particularly of salinity).

\section{REFERENCES}

Clarke, R. A., and J.-C. Gascard, 1983: The formation of Labrador Sea Water. Part I: Large-scale processes. J. Phys. Oceanogr., 13, 1764-1788.

Cuny, J., P. Rhines, P. Niiler, and S. Bacon, 2002: Labrador Sea 
boundary currents and the fate of Irminger Water. J. Phys. Oceanogr., 32, 627-647.

da Silva, A., A. C. Young, and S. Levitus, 1994: Algorithms and Procedures. Vol. 1, World Ocean Atlas 1994, NOAA Atlas NESDIS 6, $83 \mathrm{pp}$.

Dickson, R. R., J. Meincke, S. A. Malmberg, and A. J. Lee, 1988: The "Great Salinity Anomaly" in the northern North Atlantic 1968-1982. Progress in Oceanography, Vol. 20, Pergamon, 103-151.

—, I. Yashayaev, J. Meincke, B. Turrell, S. Dye, and J. Holfort, 2002: Rapid freshening of the deep North Atlantic Ocean over the past four decades. Nature, 416, 832-837.

Eden, C., and C. Böning, 2002: Sources of eddy kinetic energy in the Labrador Sea. J. Phys. Oceanogr., 32, 3346-3375.

Gent, P. R., and J. McWilliams, 1990: Isopycnal mixing in ocean circulation models. J. Phys. Oceanogr., 20, 150-155.

Houghton, R. W., and M. H. Visbeck, 2002: Quasi-decadal salinity fluctuations in the Labrador Sea. J. Phys. Oceanogr., 32, 687701.

Ikeda, M., 1987: Salt and heat balances in the Labrador Sea using a box model. Atmos.-Ocean, 25, 197-223.

Jones, J., and J. Marshall, 1997: Restratification after deep convection. J. Phys. Oceanogr., 27, 2276-2287.

Katsman, C. A., M. A. Spall, and R. S. Pickart, 2004: Boundary current eddies and their role in the restratification of the Labrador Sea. J. Phys. Oceanogr., 34, 1967-1983.

Khatiwala, S., and M. Visbeck, 2000: An estimate of the eddyinduced circulation in the Labrador Sea. Geophys. Res. Lett., 27, 2277-2280.

_ of water mass transformation in the Labrador Sea as inferred from tracer observations. J. Phys. Oceanogr., 32, 666-686.

Kuhlbrodt, T., S. Titz, U. Feudel, and S. Rahmstorf, 2001: A simple model of seasonal open ocean convection. Part II: Labrador Sea stability and stochastic forcing. Ocean Dyn., 52, 36-49.

Kieke, D., M. Rhein, L. Stramma, W. M. Smethie, D. A. LeBel, and W. Zenk, 2006: Changes in the CFC inventories and formation rates of Upper Labrador Sea Water, 1997-2001. J. Phys. Oceanogr., 36, 64-86.

Lab Sea Group, 1998: The Labrador Sea Deep Convection Experiment. Bull. Amer. Meteor. Soc., 79, 2033-2058.

Lavender, K., R. E. Davis, and W. B. Owens, 2000: Mid-depth recirculation observed in the interior Labrador and Irminger Seas by direct velocity measurements. Nature, 407, 66-99.

—, W. B. Owens, and R. E. Davis, 2005: The mid-depth circulation of the subpolar North Atlantic Ocean as measured by subsurface floats. Deep Sea Res., 52A, 767-785.

Lazier, J. R. N., 1980: Oceanographic conditions at Ocean Weather Ship Bravo, 1964-1974. Atmos.-Ocean, 18, 227-238.

_ 1995: The salinity decrease in the Labrador Sea over the past thirty years. Natural Climate Variability on Decade-to-
Century Time Scales, D. G. Martinson et al., Eds., National Research Council, 295-304.

— R. Hendry, A. Clarke, I. Yashayaev, and P. Rhines, 2002: Convection and re-stratification in the Labrador Sea, 19902000. Deep Sea Res., 49A, 1819-1835.

Legg, S., and J. McWilliams, 2001: Convective modifications of a geostrophic eddy field. J. Phys. Oceanogr., 31, 874-891.

Lilly, J. M., P. B. Rhines, M. Visbeck, R. Davis, J. R. N. Lazier, F. Schott, and D. Farmer, 1999: Observing deep convection in the Labrador Sea during winter 1994-1995. J. Phys. Oceanogr., 29, 2065-2098.

$\longrightarrow,-$, F. Schott, K. Lavender, J. Lazier, U. Send, and E. D'Asaro, 2003: Observations of the Labrador Sea eddy field. Progress in Oceanography, Vol. 59, Pergamon, 75-176.

Moore, G. W. K., and I. A. Renfrew, 2002: An assessment of the surface turbulent heat fluxes from the NCEP-NCAR reanalysis over the western boundary currents. J. Climate, 15, 2020-2037.

Pickart, R. S., D. J. Torres, and R. A. Clarke, 2002: Hydrography of the Labrador Sea during convection. J. Phys. Oceanogr., 32, 428-457.

Prater, M., 2002: Eddies in the Labrador Sea as observed by profiling RAFOS floats and remote sensing. J. Phys. Oceanogr., 32, 411-427.

Renfrew, I. A., G. W. K. Moore, P. S. Guest, and K. Bumke, 2002: A comparison of surface layer and surface turbulent flux observations over the Labrador Sea with ECMWF analyses and NCEP reanalyses. J. Phys. Oceanogr., 32, 383-400.

Rhein, M., and Coauthors, 2002: Labrador Sea Water: Pathways, CFC inventory, and formation rates. J. Phys. Oceanogr., 32, 648-665.

Sathiyamoorthy, S., and G. W. K. Moore, 2002: Buoyancy flux at Ocean Weather Station Bravo. J. Phys. Oceanogr., 32, 458474.

Smith, S. D., and F. W. Dobson, 1984: The heat budget at Ocean Weather Station Bravo. Atmos.-Ocean, 22, 1-22.

Spall, M. A., 2004: Boundary currents and water mass transformation in marginal seas. J. Phys. Oceanogr., 34, 1197-1213.

— , and D. C. Chapman, 1998: On the efficiency of baroclinic eddy heat transport across narrow fronts. J. Phys. Oceanogr., 28, 2275-2287.

Straneo, F., 2006: On the connection between dense water formation, overturning, and poleward heat transport in a convective basin. J. Phys. Oceanogr., in press.

Tucker, G. B., 1961: Precipitation over the North Atlantic. Quart. J. Roy. Meteor. Soc., 87, 147-158.

Visbeck, M., J. Marshall, and H. Jones, 1996: Dynamics of isolated convective regions in the ocean. J. Phys. Oceanogr., 26, 17211734 .

Yashayaev, I., 2004: A new study of the production, spreading and fate of Labrador Sea Water in the subpolar North Atlantic. ASOF Newsletter, Vol. 2, Arctic/Subarctic Ocean Fluxes Programme, 20-22. 